\title{
Changes in severe indices as simulated by two French coupled global climate models
}

\author{
Fabrice Chauvin ${ }^{1}$ and Sébastien Denvil ${ }^{2}$ \\ ${ }^{1}$ Centre National de Recherche Météorologique, Météo-France \\ 42 Avenue Coriolis 31057 Toulouse Cedex 01, France. \\ ${ }^{2}$ Laboratoire de Météorologie Dynamique, Institut Pierre Simon Laplace \\ Tour 45-55, Jussieu, CNRS/UPMC - Boite 99 F-75252 Paris Cedex 05 - France \\ (15 $5^{\text {th }}$ of May 2005)
}

Corresponding author address: Fabrice Chauvin

CNRM/GMGEC/UDC, Météo-France

42, avenue G. Coriolis 31057 Toulouse Cedex 01, France

E-mail: fabrice.chauvin@meteo.fr

Tel: +33(0)561079667

Fax: +33 (0)5 61079610 


\begin{abstract}
Extremes are assessed here in an attempt to validate the two French models in their representation of the second part of the $20^{\text {th }}$ century, using different sources of gridded observational datasets. Models show some ability to simulate extremal behaviour of the climate even if discrepancies are noticeable between models and observations. These may be partly due to the low resolution used for the present study simulations. Extreme indices, calculated using the STARDEX (STAtistical and Regional dynamical Downscaling of EXtremes for European regions) methodology, are investigated in different IPCC (International Panel on Climate Change) scenarios performed by the French community. Investigation of $21^{\text {st }}$ century severe indices simulated in these simulations shows some interesting features. In some parts of the world, extreme temperatures experience a more rapid increase than the mean, suggesting that the Power Density Function (PDF) may not only be shifted toward higher temperatures but also changed in its shape.

Extremes of precipitation also experience a change toward more intense precipitation events in winter and longer dry events in summer. Approaching future changes in extreme indices through their relationship to mean annual temperature may be a useful approach in multi-model studies, since it provides a measure of the sensitivity of extremes to warming conditions in these models.
\end{abstract}

\title{
1. Introduction
}

The impact of greenhouse gas (GHG) concentrations on the global temperature has been apparent for several years in observations (Jones 1994, Peterson et al. 1998 and Jones et al. 2001) and future predictions generally indicate an accelerated rate of warming with increasing GHG concentration (Houghton et al. 2001). By cumulating uncertainties due to the IPCC (International Panel on Climate Change) GHG scenarios and the diversity of different atmosphere-ocean coupled models used for prediction, the expected global warming for the end of the century is estimated at between 1.5 and $6^{\circ} \mathrm{C}$ (Houghton et al. 2001). Modelling uncertainties are essentially due to differences in 
parameterizations between models, among which cloudiness is probably the most important (Gates et al. 1999). In terms of impacts, a major effect of global warming on societies may arise from associated changes in severe events, since populations and infrastructures are very sensitive to extremes of climate. As a consequence of global warming, the shift of the temperature distribution toward higher values implies that present severe temperatures may become quite usual in the future. One consequence of this shift is that physiological thresholds may be exceeded more frequently than today, with dramatic human and natural consequences. In the French IMFREX (IMpacts des changements anthropiques sur la FRéquence des phénomènes eXtrèmes de vent, de température et de precipitations) Déqué shows that the probability of occurrence of a summer day with $\mathrm{T}_{\mathrm{x}}$ over $35^{\circ} \mathrm{C}$ is multiplied by a factor of 5 to 10 , over France, in a A2 scenario performed with ARPEGE/Climat GCM (see website on http://medias.dsi.cnrs.fr/imfrex/web/index.fr.php). There is strong evidence of observed trends in $20^{\text {th }}$ century mean temperatures (Jones et al. 2001) according to monthly mean reconstructions using a large number of global observing stations. The necessary homogenization of datasets is not as easy for daily observations as for monthly ones, since the technology lies on spatial similarity, which is not always verified for daily observations, given their variability (Mestre 2000). Dealing with extremes in climatic simulations requires particular techniques, based on statistical models, which are used to describe distributions of extreme values. The most popular is the Generalized Extreme Values (GEV) model (Coles 1999), which was used by Kharin and Zwiers (2000) to qualify changes in extreme events in a global scenario. The drawback of this approach is the scarcity of the extreme event under consideration. This makes the method inadequate for short datasets of observations. More sophisticated methods like the Generalized Pareto Distribution models (Hosking and Wallis 1987) may be used but another problem occurs with this kind of approach, linked with the accuracy of the threshold used in a future climate or the independence of variables. Another way to approach extreme sensitivity to climate change is to consider slightly less extreme events, i.e. those events that are located far from 
the mean climate but more likely to occur than outlying extremes. These may be qualified as severe events. This was the basis of the STARDEX (STAtistical and Regional dynamical Downscaling of EXtremes for European regions) project (http://www.cru.uea.ac.uk/cru/projects/stardex/), by the definition of 57 indices associated with severe conditions of temperature and precipitation over European regions. Frich et al. (2002) have documented changes in ten of the 57 severe indices during the second half of the $20^{\text {th }}$ century and this subset is part of the IPCC model outputs required for the Fourth Assessment Report (FAR), which is to be edited in 2007.

As contributors to FAR, the Centre National de Recherche Météorologique (CNRM, MétéoFrance) and the Institut Pierre et Simon Laplace (IPSL, Centre National de Recherche Scientifique) produced these indices for all the simulated scenarios. This study will present the evolution of some of the severe indices calculated, during the $20^{\text {th }}$ and $21^{\text {st }}$ centuries, according to IPCC commit, B1, A1B and B2 scenarios (Nakicenovic 2000). Models and simulations will be presented in section 2. Validation datasets will be presented in section 3. In section 4, STARDEX indices will be presented and their future changes assessed. Thus, section 5 will discuss their sensitivity to mean annual temperature. We will conclude in section 6.

\section{Models and simulations}

\section{The CNRM coupled configuration (CM3)}

The ARPEGE-Climat atmospheric model originates from the ARPEGE/IFS (Integrated Forecast System) numerical weather prediction model developed jointly by Météo-France and European Center for Medium-range Weather Forecast (ECMWF). It is a spectral atmospheric model with a hybrid $\sigma$-pressure vertical coordinate. Since the first release of the ARPEGE-Climat model (Déqué et al. 1994), many developments have been included, both dynamical and physical. Here we use the third generation of ARPEGE-Climat model (Déqué 1999). The main difference compared to former versions is the use of a two time-level semi-lagrangian numerical integration scheme with a 30 
minute time-step. The physical package includes the turbulence scheme of Louis et al. (1981), the statistical cloud scheme of Ricard and Royer (1993), and the mass-flux convective scheme with Kuo-type closure of Bougeault (1985). The radiative scheme is derived from Morcrette (1990) and is activated every 3 hours. More details about the physics of the model can be found in Geleyn et al. (1995). At the Earth's surface, the Interaction Soil-Biosphere-Atmosphere (ISBA) land surface scheme (Noilhan and Planton 1989) is used to provide boundary conditions for the computation of surface fluxes (Mahfouf et al. 1995). Although it contains the basic physics of land surface processes, the ISBA scheme only needs a few parameters depending on soil and vegetation. Vegetation types are derived from the 1-km resolution ECOCLIMAP database (Masson et al. 2003) which was developed at CNRM (Centre National de Recherches Météorologiques). The ISBA scheme has four prognostic variables for liquid water (see Douville (2003) for a complete description of the ISBA scheme).

For the IPCC simulations, ARPEGE-Climat has been coupled with oceanic OPA (Madec et al. 1998) and sea-ice GELATO (Salas-Mélia 2002) by the OASIS coupler (Terray et al. 1995). The atmospheric grid is in T63 spectral truncation (with a collocation grid of $128 \times 64$, equivalent to a $2^{\circ} 8 \times 2^{\circ} 8$ resolution) and the oceanic grid on a $182 \times 152$ resolution. The fully complete description of the IPCC configuration of the coupled model can be found in Salas-Mélia et al. (2005). The CNRM coupled configuration wil be further referenced as CM3 (for Climate Model version 3).

\section{The IPSL coupled configuration (MC2)}

The climate model IPSL-CM4 (Marti et al. 2005), used for IPCC simulations, is composed of the atmospheric LMDZ-4 (Hourdin et al 2005), oceanic ORCA (Madec et al. 1998), land surface ORCHIDEE (Krinner et al. 2005) and sea-ice LIM (Fichefet and Morales Maqueda 1997) models, coupled by the new OASIS coupler (Valcke et al. 2004). The direct and first indirect effects of sulphate aerosols have been parameterized (Pham et al. 2005). In contrast to ARPEGE-Climat, the 
dynamical part of the atmospheric model is based on a finite-difference formulation of the primitive equations of meteorology (Sadourny and Laval 1984). The grid used in this set of simulations is a $96 \times 72$ longitude/latitude (corresponding to a $3^{\circ} 75 \times 2^{\circ} 5$ equivalent resolution). The physical package includes an improved Emmanuel's convective scheme (Emmanuel 1991, Bony and Emmanuel 2001) and a representation of clouds through a probability density function of sub-grid scale total water (Le Treut and Li 1991). The effects of mountains are derived from Lott and Miller (1997) and Lott (1999). Turbulent transport in the planetary boundary layer is treated as a vertical diffusion with an eddy diffusivity depending on the local Richardson's number (Laval et al. 1981). The surface boundary layer is treated according to Louis (1981). Additionally, a tuning of the boundary layer scheme follows Krinner et al. (1997) and Grenier et al. (2000). The IPSL coupled configuration will be further referenced as MC2 (for Modélisation Climat-Cycles project).

\section{Validation datasets}

Monthly datasets of several variables have been compiled in the past and it is now easy to find a number of gridded global datasets of classical observed variables, such as temperature or precipitation. Homogenization techniques have been developed to provide long-time series at many locations worldwide, and it allows the construction of global gridded datasets long enough for validation purposes.

When calculating severe events at the annual frequency, daily data are needed. Ideally, complete and homogeneous long-time series of observations are required but homogenization techniques for daily data are not well developed compared with those for monthly data (Mestre 2000) and compilation of daily gridded datasets can be an intensive task. In the present study, three sources of observation-derived products were used, with an incomplete coverage of the world and available for only a few variables. The first dataset contains the daily minimum/maximum temperatures $\left(\mathrm{T}_{\mathrm{n}} / \mathrm{T}_{\mathrm{x}}\right)$ and precipitation for the North-American continent over the period 1951-2001 and was 
compiled by Eischeid et al. (2000). This dataset is important since it is the only dataset that allows us to calculate all the severe indices which will be used in this study. The drawback is that it is limited to the North-American continent. The second dataset is a new quasi-global $T_{n} / T_{x}$ daily dataset covering the $1946-2000$ period. It was compiled by a team from the Met Office Hadley Centre for Climate Prediction and Research (Caesar et al. 2006). This dataset provides near-global coverage but does not currently include precipitation data. Nevertheless, it is a valuable product for model validation. Finally, the third dataset only provides the number of frost days, for the period 1902-2002, as an empirical derivation of monthly minimum temperature, obtained as the mean temperature minus one-half diurnal temperature range (New et al. 2000). Although this calculation is quite empirical and does not include any station observed ground frost days, it represents a nonnegligible source of validation data for model simulations. Moreover the North American continent and eastern Europe are well covered with stations all along the period of observations. Western Europe, nevertheless, is only covered during the second part of the $20^{\text {th }}$ century (see figure 3 of New et al. 2000). Since the three datasets mentioned above cannot give a globally complete image of extreme behaviour of the atmosphere, we decided to focus on two continental regions, NorthAmerica and Europe, which have the densest observational networks.

Since the object of this study is to validate the extremes in the French scenarios, and as model climatologies should be assessed in other papers, we do not show such climatologies to avoid repetition. However, even though the two models tend to present their own biases, the global response in temperature is comparable between the two sets of French scenarios.

\section{STARDEX indices}

The European STARDEX project, supported by the European Commission (Contract no: EVK2CT-2001-00115), defined a sub-set of 57 extreme indices as interesting variables to look at for characterising the extreme behaviour of the climate (Haylock and Goodess 2004). Among these 
variables, ten were selected as IPCC diagnostics for the FAR. As part of the French contribution to the FAR, the STARDEX indices were calculated for the scenarios provided by CNRM and IPSL. Given the differences in the mean response between the two sets of scenarios (not shown here), some noticeable changes in the extreme indices may be expected.

In a first step, geographical changes for the end of $21^{\text {st }}$ century will be presented for four kinds of severe indices taken from those required by IPCC. These four indices are the annual number of frost days (TNFD), the summer heat wave duration index (HWDI), the number of winter heavy precipitation days, i.e. when precipitation is over $10 \mathrm{~mm}$ (PN10MM), and the summer maximum number of dry days, i.e. when precipitation is under $1 \mathrm{~mm}$ (PXCDD). These indices were chosen for their representation of different kinds of severe events that may induce damageable consequences for societies and human safety. From geographical changes, different regions will be selected for their homogeneous response and indices will be averaged over these regions to study their temporal evolution as well as their sensitivity to $21^{\text {st }}$ century expected warming.

\section{1th century geographical change}

Figure 1 shows the geographical changes between the end of both $20^{\text {th }}$ and $21^{\text {st }}$ century, of the annual TNFD index, for the two A2 scenarios of CM3 and MC2. As suggested by figure 1, MC2 shows a larger change than CM3, particularly over Canada, where decrease can reach more than 90 days on western coast and Alaska. Over this coast, CM3 indicates changes from 10 to 60 days from North to South. This is a very strong change since it corresponds to up to 3 months more when lands should be out of frost, with a large impact on the hydrological cycle as well as ecosystems. A big difference also exists over Scandinavian countries where MC2 shows a larger decrease than CM3. For the other places, changes are similar, particularly the position of the southern limit of changes that do not exceed 10 days. CM3, however, shows a slightly southernmost position of this limit over Mexico and Arabian peninsula. 
The impact of anthropogenic warming on the length of heat waves, represented by the summer HWDI can be seen in figure 2. HWDI is the maximum number of consecutive days for which $T_{x}$ is at least $5^{\circ} \mathrm{C}$ higher than the 1961-90 normal. Except over the high latitudes in CM3 and ITCZ in MC2, an increase is noticeable over all parts of the world with higher intensities evident in CM3 over the countries surrounding the Mediterranean sea, the central United States and western Canada, while MC2 shows more homogeneous change, except over Northern Canada, Northern Europe and former USSR. These patterns may be attributed to two distinct responses of the surface to changing climate. Anthropogenic warming forces a shift in the temperature distribution which implies, due to its definition, a substantial increase in HWDI. If temperatures are warmer in the future than in the present without changing the reference threshold, the number of days exceeding the threshold will be systematically higher, leading to a higher probability of more consecutive days over this threshold. In addition to this mechanical effect, changes in precipitation may add a negative feedback which leads to an increase in HWDI where summer precipitation is reduced. This feedback is explained in Douville (2005) by the double effect of reduced precipitation on decreased soil moisture as well as a decreased cloud forcing. This precipitation feedback will be discussed later on, when interpreting the non-linear relation between HWDI and mean temperature, in section 5 .

Figure 3 shows changes in winter PN10MM for the CM3 and MC2 A2 scenarios. The two simulations show a fairly similar response to global warming for this index, with an increased activity of severe precipitation over northern mid-latitudes, specially over Europe and Canada, as well as in the ITCZ and a decrease over tropical latitudes and Mediterranean countries, except over Spain and Australia for. North America changes are stronger in MC2 and European ones in CM3. Mid-latitudes changes are probably due to an enhanced baroclinic activity which may be expected in a warmer climate or, at least, a moister associated atmosphere, leading baroclinic systems to 
produce more rainfall for the same activity. Tropical decrease may be a result of reduced soil moisture associated with more dryness.

This increased dryness is particularly marked in summer when the PXCDD index experiences an increase over a major part of extra-tropical latitudes (figure 4). The two simulations differ only over the western coast of the USA, where CM3 indicates an increase while MC2 indicates a decrease, Arabian peninsula, where only CM3 indicates an increase and north-western Indian peninsula where only MC2 show a decrease which may be associated with an enhanced monsoon activity. Over North-African continent, CM3 shows a decrease of dryness in the western and an increase in the eastern part. It is in agreement with changes in mean precipitation field associated with African monsoon (not shown). The two simulations agree on a decrease of dry sequences in the ITCZ, in agreement with its enhanced activity. It can be noticed, in both simulations, that regions where PXCDD strongly increase significantly are also associated with particularly increased HWDI, confirming the strong link between heat waves and lack of precipitation. This also suggests that precipitation represents a strong feedback on extreme temperatures and that the ability of models to simulate rainfall should be enhanced to better predict the impact of anthropogenic warming on these extremes.

\section{Regional average validation and evolution}

Although STARDEX indices (SI in the following) have been defined as station-dependent and give, by essence, local information on extreme behaviour of the climate, one may consider that such indices are representative of the surrounding region, as represented by a gridpoint in an atmospheric analysis. This is probably true for temperature related indices, since this variable is spatially homogeneous. It is more questionable for precipitation related indices, although winter heavy precipitation is, most of the time, associated with synoptic scale systems and summer dryness is generally widespread over countries. In order to assess the impact of gridding process on 
the calculation of SI, one experiment may be considered. First, SI should be calculated, as it is done in this study, from daily gridded analysis such as the recent $T_{x} / T_{n}$ dataset covering the period 19462000 produced at Met Office (Caesar et al. 2006). On an other hand, apply the gridding process to SI calculated from each observing station. The comparison of the two resulting SI should give some information on the gridding impact on the extreme behaviour of the atmosphere. Nevertheless, it is not under the scope of this study to assess this point and it is hypothesized that daily gridded data are able to capture severe events in the same way as station observations do.

At the regional scale ( $\sim 5000 \mathrm{kms}$ by opposition to local scale which is $\sim 100-500 \mathrm{kms})$ averaged indices provide interesting information on the ability of the models to represent severe events, although we found it necessary to limit the spatial extension of the regions in order to avoid melting different climates in a same region. In this study, five regions were selected for their homogeneous response of indices. These regions have been reported on figures 1 to 4 as red boxes. Boxes were distributed over the 4 figures for more clarity. The five selected regions are Alaska $\left(58-70^{\circ} \mathrm{N}, 165-\right.$ $\left.105^{\circ} \mathrm{W}\right)$, Canada $\left(38-58^{\circ} \mathrm{N}, 130-70^{\circ} \mathrm{W}\right)$, USA $\left(28-38^{\circ} \mathrm{N}, 120-75^{\circ} \mathrm{W}\right)$, Europe $\left(45-60^{\circ} \mathrm{N}, 15^{\circ} \mathrm{W}-\right.$ $\left.45^{\circ} \mathrm{E}\right)$ and Mediterranean countries $\left(28-45^{\circ} \mathrm{N}, 15^{\circ} \mathrm{W}-45^{\circ} \mathrm{E}\right)$. Figure 5 shows the time evolution of averaged TNFD over the five regions for both CNRM and IPSL A2 scenarios along the 240 years of simulation. Also represented are the equivalent averages for the three kinds of observed dataset over North-America and two kinds over Europe (Eischeid dataset is available only over NorthAmerica). Given the large variability in observations, for which differences may reach 50 days over Canada, the two models appear to simulate quite reasonably the index. While the two simulations are in a good agreement over Europe, the CM3 tends to be colder than MC2 over North America, resulting in a difference of respectively 20, 30 and 40 days for Alaska, Canada and USA. Over Alaska and Canada, TNFD decrease more quickly in MC2 than in CM3, leading to a difference of 60 days at the end of $21^{\text {st }}$ century. Over Europe, the two scenarios are similar in their present TNFD ( $\sim 160$ days $)$ as well as their decreasing rate, leading to 80 days at the end of $21^{\text {st }}$ century. 
Mediterranean countries are not caught in the same way in the two scenarios since CM3 shoes 20 more days than MC2 at the beginning of the period. The decreasing rates are different such as it results in a common 15-20 days at the end of $21^{\text {st }}$ century. Concerning observations, a decrease is noticeable in all the regions during $20^{\text {th }}$ century, giving some credit to the simulated decrease in models. Over Mediterranean countries, the Met Office dataset (Caesar et al. 2006) even shows a decreasing shift between 1950s and 1960s which may be attributable to observation deficiencies. In both scenarios, the decrease is accelerated during the $21^{\text {st }}$ century, even if it is noticeable as soon as beginning of the $20^{\text {th }}$. It should be noticed that MC2 is run with months of 30 days long, leading to years having 360-days instead of 365 or 366 . We assume that the impact of this different duration of the year is negligible since the difference in total number of days is $1.4 \%$.

The HWDI (fig. 6) shows a strong trend after year 2000 for the two scenarios, except over Alaska where CM3 keeps it constant, as suggested by figure 2. Before, the maximum length of hot spells does not reach 5 days in major regions, except over USA and Europe, in agreement with observations, and it can reach more than 60 days at the end of $21^{\text {st }}$ century, over the Mediterranean, in CM3. The increase in HWDI is associated with an increased variance, suggesting that warming keeps and even enhance the strong interannual variability which exists in the index. Nevertheless, although this increase in variance, low HWDI years at the end of $21^{\text {st }}$ century are still far higher than present ones. It seems that there is a threshold effect in HWDI, since its increase only begins at the end of the $20^{\text {th }}$ century while the $T_{x}$ warming begins earlier. This threshold is essentially due to the choice of the $90^{\text {th }}$ percentile calculation on the 1961-1990 period. This point will be assessed in the next section.

We will now focus on precipitation-related indices, one for strong events in winter (PN10MM) and the other concerning summer dry spells (PXCDD). These two indices can only be validated over North America since only the Eischeid's dataset provides daily precipitation observations. Figure 7 shows the time evolution of winter PN10MM for the five regions previously identified. The two 
models agree over Europe and the Mediterranean. They differ over the whole North America, where CM3 seems to be more realistic over Alaska and Canada. Strong winter precipitation events increase over Alaska and Canada, as well as Europe, for the two scenarios. The interannual variability is more marked over low than over high latitudes. USA and the Mediterranean do not show any marked evolution (except a slight increase over USA for CM3). Variance do not seem to change between the beginning and the end of the period.

Summer dry spells (fig. 8) are in good agreement with observations for MC2 over Alaska and Canada while CM3 underestimates the dry spell duration. It is more realistic than MC2, nevertheless, over USA. $21^{\text {st }}$ century evolution of PXCDD depends on latitude and model. MC2 shows a 4 days increase over Alaska while CM3 does not show any change. Both CM3 and MC2 show slight increase over Canada, USA and the Mediterranean. MC2 and CM3 differ over Europe with a stronger increase for CM3. There is no change in the interannual variability of both precipitation indices during the whole period of simulation. These two indices suggest that the hydrological cycle will be enhanced in the future, with stronger events in winter, and more dryness, in summer. These results have already been shown, for the ARPEGE model mean precipitation fields, in Gibelin and Déqué (2003). Durman et al. (2001) found European increased winter heavy precipitations in both GCM and Regional Climate Model (RCM). Frich et al. (2002) found an increase, in the last 50 years, of pn10mm for a large part of Northern hemisphere. However, they found a decrease of PXCDD, in contradiction with our results. Kiktev et al. (2003) also found a decrease. The apparent inconsistency probably comes from sampling effect as well as choice of the period of evaluation. Figure 9 shows the temporal evolution of PXCDD averaged over Europe (top) and USA (bottom) on the 1950-2000 period. For USA, the averages from Eischeid's dataset have also been reported. The figure illustrates that the observed decrease during the second part of the $20^{\text {th }}$ century is well captured by MC2. CM3, nevertheless, shows a very slight increase which has nothing to do with the one observed in figure 8 between end of $20^{\text {th }}$ and $21^{\text {st }}$ centuries. Thus, one 
should be careful in interpreting observed trends on short timescales since they may be attributable to sample effects. Considering larger periods may change the conclusions about the warming effect on precipitation behaviour.

\section{Sensitivity of indices to mean temperature increase}

One question which may be interesting to assess is whether the extreme indices vary linearly with mean annual temperature, since the latter is often used as a measure of global warming. In the case of linear relation, an increasing rate may even be attributed to each index relatively to temperature change. We have seen in the previous chapter that the relation was not linear for HWDI. Figure 10 shows a linear relation of TNFD with mean temperature at the regional scale, over four of the five selected domains. The Mediterranean, nevertheless, present a non-linear decrease of frost days with mean annual temperature. In fact, linearity of the relation is apparent in the different scenarios commit, B11, A1B and A2, except where the number of frost days comes close to zero. Thus, the behaviour becomes asymptotic. No feedback seems to operate on the change of this variable. Of course, the relation between the decrease of frost days and the annual temperature may vary from one place to another, but, at the regional scale, and given that gridpoints have a similar behaviour, the two French models show similar sensitivities, even if MC2 shows an underestimation of approximately one month over USA. The decreasing rate is between $7-11$ days $/{ }^{\circ} \mathrm{C}$ over the North American continent and $\sim 13$ days $/{ }^{\circ} \mathrm{C}$ for Europe. As it was said earlier, for the Mediterranean, the relation between number of frost days and mean annual temperature is not linear and the decreasing rates evolves from $\sim 13$ days $/{ }^{\circ} \mathrm{C}$ for lowest to 5 days $/{ }^{\circ} \mathrm{C}$ for highest temperatures. Those rates seem to be fairly realistic when compared with observations, even if CRU dataset shows a sensitivity that is quite different over Alaska. This may be an indication that the latter is too large, due to the way frost days are estimated in New et al. (2000). Indeed, it results from a complex and non-linear relationship between frost days and minimum daily temperature. This relationship was calibrated 
with United Kingdom observations only and may not be accurate for highest latitudes. The Eischeid's dataset shows a slightly greatest decreasing rate compared with other observation sources over USA.. As expected, figure 11 shows a non-linear relation between HWDI and mean annual temperature, the former increasing more quickly than the latter. Figure 12 shows, for Europe (top) and the Mediterranean (bottom), the value of the $90^{\text {th }}$ percentile of $T_{x}$ relatively to annual mean temperature for both scenarios. For the Mediterranean, figure 12 agrees with Beniston and Stephenson (2004) who found a linear relation between the mean and the $90^{\text {th }}$ percentile of summer $\mathrm{T}_{\mathrm{x}}$ in two Swiss stations, with a regression coefficient not far from 1 (1.18 for Basel and 0.94 for Säntis). Nevertheless, Europe shows a non-linear relationship in CM3 which suggests that extreme temperatures increase more quickly that the mean. It implies that non-linear processes act to accelerate the increase of the maximum temperature (or to limit the increase of the mean). Midlatitudes baroclinic processes may be such non-linear feedbacks. What is suggested here is that the length of hot spells, as defined by HWDI, may increase more quickly than mean temperature, resulting in more dramatic effects for mid-latitudes continental regions than suggested by only considering the increase in the mean temperature. The question that may arise, at this point of the discussion is whether this increase is the result of a change in the shape or scale of the $T_{x}$ distribution associated with the increase of the mean. To assess this question a new HWDI was calculated relatively to a varying 30-year reference, instead of the fixed 1961-90 normal as used in the STARDEX definition. Thus, if change in the $\mathrm{T}_{\mathrm{x}}$ distribution is limited to the first order moment, it should result in no change in the HWDI. It is an other way to ask the question of the extreme character of the climate. The severe events of the future climate may be calculated comparatively to present or future mean climate itself. In the second case, what is assessed is really the extreme character of the future climate. In the first case, this is a shift from extreme to normal conditions that is assessed, between present and future climate. Consequences differ in the two cases because the necessary adaptation of societies may not be the same. If changes appear in how climate 
extremes withdraw from the mean, structural changes of societies should take it into account. As an illustration of the non-linear effect of increasing temperature on extreme indices, figure 13 shows the new HWDI for the five regions previously defined. The global period has been reduced by 15 years at the beginning and the end, due to the calculation of the moving 30-year normal. Figure 13 shows that changes in the new HWDI are quite smaller than those of the previous formulation. Nevertheless, even small, the trend is positive, especially over Europe, where the index evolves from 1.6 to 3.1 days along the period, essentially due to more frequent events in the $21^{\text {st }}$ century. Trends in other regions are not so marked, but Alaska and Canada see their strongest events during the $21^{\text {st }}$ century.

To explain why hot waves length increases more quickly than mean temperature, one may consider the increase in dryness over mid-latitudes of North-America and Europe in all the future scenarios (figure 15). More dryness favours large diurnal amplitudes and maximum temperatures. The relationship between precipitation and temperature is complex since both fields may influence each other. Increasing temperature favours convection but enhanced precipitation will, in turn, act as a negative feedback on the temperature. The resulting equilibrium between the two variables may be sensitive to the kind of precipitation regimes encountered in a warmer climate. The sensitivity of precipitation indices to mean temperature shows a changing character between winter and summer seasons (figures 14 and 15). In winter, number of days with precipitation greater than $10 \mathrm{~mm} \mathrm{day}^{-1}$ increases with mean temperature in northern and southern parts of both Europe and North America. However, no sensitivity is observed in the Eischeid's dataset, at least in the temperature range for which observations are available. On the other hand, summer dryness is also enhanced with increasing temperature, except for CM3 over Canada. This lack of sensitivity is also noticeable in figure 4, where Canada experiences no change in the PXCDD index. Observation can not account for such a sensitivity, even if an increasing rate of PXCDD change with temperature may be seen 
over the three North-American regions. Temperature range of observations is, nevertheless, too short to conclude in the existence of such a relation or not.

\section{Conclusions}

This study focused on severe indices as defined in the STARDEX project and asked in the IPCC diagnostics for the FAR. What is original, here, is to consider severe indices at the regional scale and to define large places where the behaviour of extremes seems to be homogeneous. As an illustration of the use of these averaged indices, two temperature-related and two precipitationrelated indices were presented, as observed and simulated by the two French CNRM and IPSL models. Although there are some differences in present climate modelling of the indices, the two models agree in their relationship with mean temperature as well as its future evolution. If the linear relationship between mean temperature and number of annual frost days suggests, as expected, a dramatic decrease of frost days in the future, the non-linearity of the relationship between mean temperature and hot spells is even more worrying since hot spells could increase far more quickly than the expected mean warming simply suggests. Such a non-linear relation is found over Europe for CM3 while the other regions show linear relations and a fairly similar rate of increase for mean annual temperature and $90^{\text {th }}$ percentile of maximum temperature. For these regions, HWDI increases principally due to a mechanical shift of the mean temperature distribution. Thus, HWDI, by its non-linear definition, grows more quickly than the mean. For Europe, this is not exactly the case, since the $90^{\text {th }}$ percentile already grows non-linearly with the mean. So, to understand changes in European HWDI, a change in shape and scale of the temperature distribution must be considered additionally to its shift. We assume that this is due to interactions with moist processes. Weak linear relationships exist between precipitation indices and temperature, at the regional scale, although a tendency can be deduced from future scenarios, with increases in both winter heavy precipitation events and summer dry spells. This is coherent with an increase in the mean annual 
water cycle already found in other studies (Douville et al. 2002). For summer dry spells, the apparent incoherency between scenarios, which show an increase of PXCDD between present and future climate, and observations, which show a decrease over the last 50 years, may be due to a sampling effect. Indeed, if the period of scenarios is limited to the observation one, there is no more discrepancies, at least for IPSL scenario.

The way to relate indices to mean temperature may be a useful tool for modelling validation purposes. On the same graph, one may see the biases in both model temperature and/or precipitation indices as well as departures from observations in the increasing/decreasing rate of change relatively to temperature warming. In addition to the future changes in the extreme indices, these graphics bring additional information on their rate of change, highlighting those which are the most sensitive to warming and should be, thus, the focus of attention. Moreover, these graphs are good indicators of changes that may occur in the relationship between extremes and mean temperature, due to the different feedbacks acting in a warmer climate. This approach do not pretend to assess extreme changes in all their complexity, especially where changes occur in scale and shape of daily variables distributions. Nevertheless, it is evident that there is some spatial coherency for severe indices which allow to condense the information provided by scenarios. In a multi-model intercomparison, such as the one that the actual IPCC exercise undertakes, such integrated approach can have some utility. Of course, station-dependent detailed studies are still needed to understand the exact relationship between climate and its extremes, and it should be clearly assessed with all the known statistical tools. But it is also useful to recognize that climate presents some spatial coherency allowing regional extrapolation which may be useful for policy makers. Further studies may address the geographical distribution of changing rates of extremes relative to mean temperature and highlight regions to pay attention for. But the limitation of this approach is that it may only be applied to indices which vary linearly with mean temperature. 


\section{Acknowledgments}

Sources of observations were kindly provided by Alexander Gershunov, for the North American dataset and John Caesar for the recently achieved HadGHCND dataset from Met Office.

A special thank should be addressed to David Salas y Mélia and Sophie Tyteca for the performance of the CNRM simulations and Jean-Louis Dufresne for the IPSL ones. This work has been undertaken in the frame of the French ESCRIME project, supported by PNEDC (Programme National d'Etude de la Dynamique du Climat) and GICC (Gestion et Impacts du Changement Climatique), and coordinated by Laurent Terray from CERFACS. 


\section{References}

Balling Jr, R.C., J.A. Skindlov and D.H. Phillips, 1990: The impact of increasing summer temperature on extreme maximum and minimum temperatures in Phoenix, Arizona. J. Clim., 3, 1491-1494.

Arkin, P. and J. Janowiak,1991: Analyses of the global distribution of precipitation. Dyn. Atmos. Oceans, 16, 5-16.

Béniston, M. and H.F. Diaz, 2004: The 2003 heat wave as an example of summers in a greenhouse climate? Observations and climate model simulations for Basel, Switzerland. Global and Planetary Change, 44, 73-81.

Béniston, M. and D. B. Stephenson, 2004: Extreme climatic events and their evolution under changing climatic conditions. Global and Planetary Change 44, 1-9.

Bony, S., and K. A. Emmanuel, 2001: A parameterization of the cloudiness associated with cumulus convection; evaluation using TOGA COARE data. J. Atmos. Sci., 58, 3158-3183.

Bougeault, P., 1985: A simple parameterization of the large-scale effects of cumulus convection. Mon. Wea. Rev., 113, 2108-2121.

Caesar, J., L. Alexander, and R. Vose (2006), Large-scale changes in observed daily maximum and minimum temperatures: Creation and analysis of a new gridded data set, J. Geophys. Res., 111, D05101, doi:10.1029/2005JD006280.

Cassou, C., L. Terray and A.S. Phillips, 2005: Tropical Atlantic influence on European heat waves, J. Clim., 18, 2805-2811.

Coles, S, 2001 : An Introduction to Statistical Modeling of Extreme Values. London: SpringerVerlag.

Déqué, M., 1999: Documentation ARPEGE-CLIMAT.Technical report, Centre National de Recherches Météorologiques, Météo-France, Toulouse, France. 
Déqué, M. and C. Dreveton and A. Braun and D. Cariolle, 1994: The ARPEGE/IFS atmospheric model: a contribution to the French community climate modeling. Clim. Dyn., 10, 249-266.

Douville, H. and F. Chauvin and S. Planton and J.-F. Royer and D. Salas y Mélia and S. Tyteca, 2002: Sensitivity of the hydrological cycle to increasing amounts of greenhouse gases and aerosols. Clim. Dyn., 20, 45-68. DOI 10.1007/s00382-002-0259-3.

Douville, H., 2003: Assessing the influence of soil moisture on seasonal climate variability with AGCMS. J. Climate., 4, 1044-1066.

Douville, H. and J.-F. Royer, 1997: Influence of the temperate and boreal forests on the Northern hemisphere climate in the Météo-France climate model, Clim. Dyn., 13, 57-74.

Douville, H., D. Salas-Mélia and S. Tyteca, 2005: On the tropical origin of uncertainties in the global land precipitation response to global warming. Clim. Dyn., 26, 367-385. DOI $10.1007 / \mathrm{s} 00382-005-0088-2$.

Dreveton, C. and M. Déqué and J.F. Geleyn, 1993: Interactions of physical parameterizations in the climate version of the ARPEGE/IFS model. Beitr. Phys. Atmos., 66, 283-303.

Durman, C. F., J. M.Gregory, D. C. Hassell, R. G. Jones and J. M. Murphy, 2001: A comparison of extreme European daily precipitation simulated by a global and a regional climate model for present and future climates. QJR. Meteorol. Soc., 127, 1005-1015.

Eischeid, J.K., P.A. Pasteris, H.F. Diaz, M.S. Plantico and N.J. Lott, 2000: Creating a serially complete, national daily time series of temperature and precipitation for the western Unites States. J. Appl. Meteor., 29, 1580-1591.

Emanuel, K. A., 1991: A scheme for representing cumulus convection in large-scale models. J. Atmos. Sci., 48, 2313-2335.

Fichefet, T., and M. A. Morales Maqueda, 1997: Sensitivity of a global sea ice model to the treatment of ice thermodynamics and dynamics. J. Geophys. Res., 102, 2609-2646. 
Frich, P., L.V. Alexander, P. Della-Marta, B. Gleason, M. Haylock, A.M.G. Klein Tank and T. Peterson, 2002: Observed coherent changes in climatic extremes during the second half of the twentieth century. Climate Reasearch,19, 193-212.

Gates, W.L., J.S. Boyle, C. Covey, C.G. Dease, C.M. Doutriaux, R.S. Drach, M. Fiorino, P.J. Gleckler, J.J. Hnilo, S.M. Marlais, T.J. Phillips, G.L. Potter, B.D. Santer, K.R. Sperber, K.E. Taylor and D.N. Williams, 1999: An overview of the results of the Atmospheric Model Intercomparison Project (AMIP I). Bull. Am. Met. Soc., 80, 29-55.

Gibelin, A.-L. and M. Déqué, 2003: Anthropogenic climate change over the mediterranean region simulated by a global variable resolution model. Clim. Dyn., 20, 327-339.

Grenier, H., H. Le Treut, and T. Fichefet, 2000: Ocean-atmosphere interactions and climate drift in a coupled general circulation model, Climate Dynamics, 16, 701-717.

Haylock, M. and C. Goodess, 2004: Interannual variability of European extreme winter rainfall and links with mean large-scale circulation. International Journal of Climatology, 24, 759-776.

Hosking, J.R.M. and J.R. Wallis, 1987: Parameter and quantile estimation for the generalized Pareto distribution, Technometrics, 29(3), 339-349.

Houghton, J. T., Y. Ding, D.J. Griggs, M. Noguer, P. J. van der Linden and D. Xiaosu, 2001: Contribution of Working Group I to the Third Assessment Report of the Intergovernmental Panel on Climate Change (IPCC). Cambridge University Press, UK. pp 944.

Hourdin, F., I. Musat, S. Bony, P. Braconnot, F. Codron, J.-L. Dufresne, L. Fairhead, M.-A. Filiberti, P. Friedlingstein, J.-Y. Grandpeix, G. Krinner, P. Levant, Z.-X. Li and F. Lott: The LMDZ4 general circulation model: climate performance and sensitivity to parametrized physics with emphasis on tropical convection (Submitted to Clim. Dyn., 2005).

Hulme, M., 1992: A 1951-80 global land precipitation climatology for the evaluation of general circulation models. Clim. Dyn., 7, 57-72. 
Jones, P.D., 1994: Hemispheric surface air temperature variations: a reanalysis and an update to 1993. J. Climate, 7, 1794-1802.

Jones, P.D., T.J. Osborn, K.R. Briffa, C.K. Folland, E.B. Horton, L.V. Alexander, D.E. Parker and N.A. Rayner, 2001: Adjusting for sampling density in grid box land and ocean surface temperature time series. J. Geophys. Res., 106, 3371-3380.

Kharin, V.V. and F.W. Zwiers, 2000: Changes in the extremes in an ensemble of transient climate simulation with a coupled atmosphere-ocean GCM. J. Clim., 13, 3760-3788.

Kiktev, D., D.M.H. Sexton, L. Alexander and C.K. Folland, 2003: Comparison of modelled and observed trends in indices of daily climate extremes. J. Clim., 16, 3560-3571.

Krinner, G., N. Viovy, N. de Noblet-Ducoudré, J. Ogée, J. Polcher, P. Friedlingstein, P. Ciais, S. Sitch, and C. Prentice, 2005: A dynamic global vegetation model for studies of the coupled atmosphere-biosphere system. Glob. Biogeochem. Cyc., 19, GB1015, doi:10.1029/2003GB002199.

Laval, K., R. Sadourny and V. Serafini, 1981: Land surface processes in a simplified general circulation model. Geophys. Astrophys. Fluid Dyn., 17, 129-150.

Le Treut, H., and Z. X. Li, 1991: Sensitivity of an atmospheric general circulation model to prescribed SST changes: feedback effects associated with the simulation of cloud optical properties. Climate Dynamics, 5, 175-187.

Lott, F., 1999: Alleviation of stationary biases in a GCM through a mountain drag parametrization scheme and a simple representation of mountain lift forces. Mon. Wea. Rev., 127, 788-801.

Lott, F., and M. Miller, 1997: A new sub-grid scale orographic drag parametrization: its formulation and testing., Q. J. R. Meteorol. Soc., 123, 101-128.

Louis, J.-F., 1979: A parametric model of vertical eddy fluxes in the atmosphere. Boundary-layer Meteorol., 17, 187-202. 
Louis, J.-F., M. Tiedtke and J.-F. Geleyn, 1981: A short history of the operational PBLparameterization at ECMWF. ECMWF Workshop Planetary Boundary Layer Parameterization, 25-27 November 1981, ECMWF, Reading, UK, pages 59-80.

Madec, G., P. Delecluse, M. Imbard, and C. Lévy, 1998: Opa 8.1, ocean general circulation model reference manual. Notes du Pôle de modélisation 11, Institut Pierre-Simon Laplace (IPSL).

Marti, O., P. Braconnot, J. Bellier, R. Benshila, S. Bony, P. Brockmann, P. Cadule, A. Caubel, S. Denvil, J.-L. Dufresne, L. Fairhead, M.-A. Filiberti, M.-A. Foujols, T. Fichefet, P. Friedlingstein, J.-Y. Grandpeix, F. Hourdin, G. Krinner, C. Lévy, G. Madec, I. Musat, N. de Noblet, J. Polcher and C. Talandier, 2005: The new IPSL climate system model: IPSLCM4. Tech. Rep., Institut Pierre Simon Laplace, http://igcmg.ipsl.jussieu.fr/Doc/IPSLCM4.

Masson, V., J.-L. Champeaux, F. Chauvin, C. Meriguet and R. Lacaze, 2003: A global database of land surface parameters at $1-\mathrm{km}$ resolution in meteorological and climate models. $\mathrm{J}$. Climate., 16, 1261-1282.

Mestre O., 2000 : Méthodes statistiques pour l'homogénéisation de longues séries climatiques. PhD thesis, Université Paul Sabatier Toulouse, France.

Mitchell, T.D. and P.D. Jones, 2005: An improved method of constructing a database of monthly climate observations and associated high-resolution grids. Int. J. Climatol., 25, 693-712.

Moberg A. and P.D. Jones, 2004: Regional climate model simulations of daily maximum and minimum near-surface temperatures across Europe compared with observed station data 1961-1990. Clim. Dyn., 23, 695-715.

Morcrette, J.-J., 1990: Impact of changes to the radiation transfer parameterizations plus cloud optical properties in the ECMWF model. Mon. Wea. Rev., 118, 847-873.

Nakicenovic, N. and R. Swart, 2000: Special Report of the Intergovernmental Panel on Climate Change. Cambridge University Press, UK. pp 570 
New M.; M. Hulme and P. Jones, 2000: Representing twentieth-century space-time climate variability. Part II: development of 1901-96 monthly grids of terrestrial surface climate. J Clim., 13, 2217-2238.

Noilhan, J. and S. Planton, 1989: A simple parameterization of land surface processes for meteorological models. Mon. Wea. Rev., 117, 536-549.

Pham, M., O. Boucher and D. Hauglustaine, 2005: Changes in atmospheric sulfur burdens and concentrations and resulting radiative forcings under IPCC SRES emission scenarios for 1990-2100. J. Geophys. Res., 110, D06112, doi: 10.1029/2004JD005125.

Peterson, T.C., D.R. Easterling, T.R. Karl, P. Groisman, N. Nicholls, N. Plummer, S. Torok, I. Auer, R. Boehm, D. Gullett, L. Vincent, R. Heino, H. Tuomenvirta, O. Mestre, T. Szentimrey, J. Salinger, E.J. Førland, I. Hanssen-Bauer, H. Alexandersson, P. Jones and D.Parker, 1998b: Homogeneity adjustments of in situ atmospheric climate data: a review. Int. J. Climatol., 18, 1495-1517.

Reynolds, R.W. and T.M. Smith, 1994: Improved global sea surface temperature analyses using Optimum Interpolation. J. Clim., 7, 929-948.

Ricard, J.-L. and J.-F. Royer, 1993: A statistical cloud scheme for use in an AGCM. Annales Geophysicae, 11, 1095-1115.

Sadourny, R. and K. Laval, 1984: January and July performance of the LMD general circulation model. In New perspectives in Climate Modeling, edited by A. Berger and C. Nicolis, Elsevier, pp. 173-197, Elsevier, Amsterdam.

Salas-Mélia, D. , 2002 : A global coupled sea ice-ocean model. Ocean Modelling, 4, 137-172.

Salas-Mélia D., F. Chauvin, M. Déqué, H. Douville, J.F. Guérémy, P. Marquet, S. Planton, J.F. Royer and S. Tyteca: Description and validation of the CNRM-CM3 global coupled model (submitted to Clim. Dyn., sept 2005). 
Terray, L., E. Sevault, E. Guilyardi, and O. Thual, 1995: The OASIS coupler user guide version 2.0. Tech. Rep. TR/CMGC, CERFACS, Toulouse, France.

Valcke, S., A. Caubel, R. Vogelsang and D. Dedat, 2004: OASIS3 ocean-atmosphere sea ice soil users's guide. Tech. Rep. TR/CMGC/04/68, CERFACS, Toulouse, Zhang, X., W.D. Hogg and E. Mekis, 2000: Spatial and temporal characteristics of heavy precipitation events over Canada. J. Clim., 14, 1923-1936.

Zwiers, F.W. and V.V. Kharin, 1998: Changes in the extremes of the climate simulated by CCC GCM2 under CO2 doubling. J. Clim., 11, 2200-222. 


\section{List of Figures}

Figure 1: Difference in the average number of annual frost days between 1970-99 and 2070-99 periods, for CM3 (top) and MC2 (bottom) in the A2 scenario. Gridpoints for which the difference is non significant at the $80 \%$ level are shaded in grey. Limits of Alaska and Europe (top) and Canada (bottom) domains have been reported.

Figure 2: Same as figure 5 for maximum number of summer heat wave days. Limits of Mediterranean domain (top) has been reported. Limits of Canada, USA and Europe domains (top) have been reported.

Figure 3: Same as figure 5 for number of winter days with precipitation exceeding $10 \mathrm{~mm}$.

Figure 4: Same as figure 5 for maximum number of summer consecutive days with precipitation less than $1 \mathrm{~mm}$. Limits of USA and Mediterranean domains (top) have been reported.

Figure 5: Evolution of annual number of frost days for Alaska (top left), Canada (top right), USA (middle left), Europe (bottom left) and Mediterranean countries (bottom right). Horizontal axis represents the years 1860 to 2100 . Vertical axis represents the number of days. Observations are plotted as full triangles (Eischeid et al. 2000), stars (Caesar et al. 2005) or empty squares (New et al. 2000) and lines are for CM3 (dashed) and MC2 (dotted) $20^{\text {th }}$ century $+\mathrm{A} 2$ scenario simulations.

Figure 6: Same as figure 5, but for maximum number of summer heat wave days.

Figure 7: Same as figure 5, but for number of winter days with precipitation exceeding $10 \mathrm{~mm}$.

Figure 8: Same as figure 5, but for maximum number of summer consecutive days with precipitation less than $1 \mathrm{~mm}$.

Figure 9: Evolution of maximum number of summer consecutive days with precipitation less than 1 mm over Europe (top) and USA (bottom). Horizontal axis represents the years 1950 to 2000. Vertical axis represents the number of days. MC2 is plotted as empty squares and 
regression line is dashed, CM3 is plotted as full circle and regression line is dash-dotted. Observations (Eischeid et al. 2000) are plotted as triangles and regression line is solid.

Figure 10: Sensitivity of annual number of frost days to mean annual temperature for Alaska (top left), Canada (top right), USA (middle left), Europe (bottom left) and Mediterranean countries (bottom right). Horizontal axis represents the mean annual temperature in ${ }^{\circ} \mathrm{C}$. Vertical axis represents the number of days. Observations are plotted as full triangles (Eischeid et al. 2000), stars (Caesar et al. 2005) or empty squares (New et al. 2000) and simulations for the $20^{\text {th }}$ century and scenarios commit, B1, A1B and A2 are represented as full grey circles (CM3) and brown full squares (MC2).

Figure 11: Same as figure 11 for maximum number of summer heat wave days.

Figure 12: Same as figure 10 for $90^{\text {th }}$ percentile of $T_{x}$ over Europe (top) and the Mediterranean (bottom).

Figure 13: Same as figure 6 for maximum number of summer heat wave days calculated from yearly moving normals.

Figure 14: Same as figure 9 for number of winter days with heavy precipitation (exceeding $10 \mathrm{~mm}$ ).

Figure 15: Same as figure 9 for maximum number of summer consecutive dry days (with precipitation less than $1 \mathrm{~mm})$. 


\section{tnid (YEAR)}
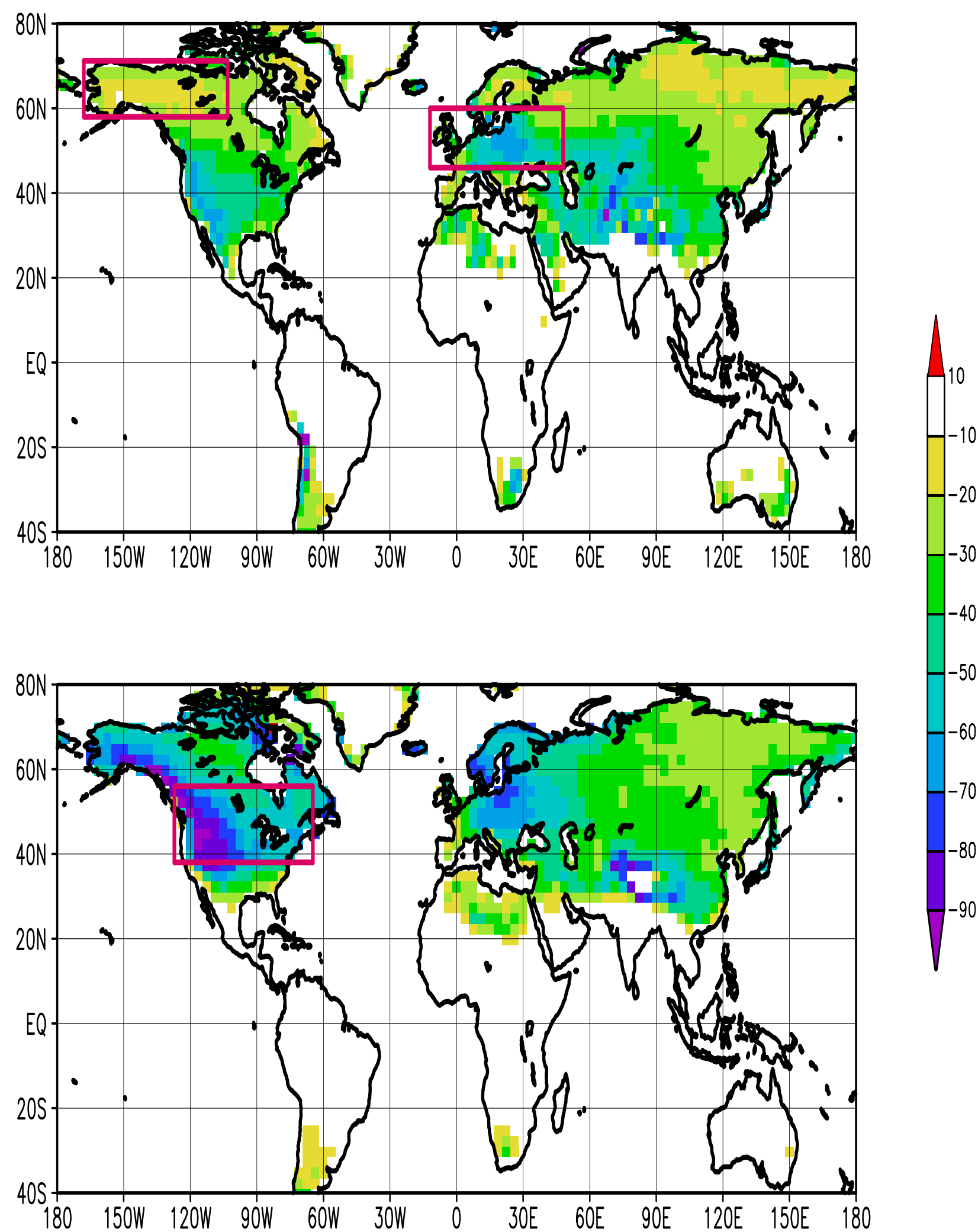

Figure 1: Difference in the average number of annual frost days between 1970-99 and 2070-99 periods, for CM3 (top) and MC2 (bottom) in the A2 scenario. Gridpoints for which the difference is non significant at the $80 \%$ level are shaded in grey. Limits of Alaska and Europe (top) and Canada (bottom) domains have been reported. 
txhwd (JJA)
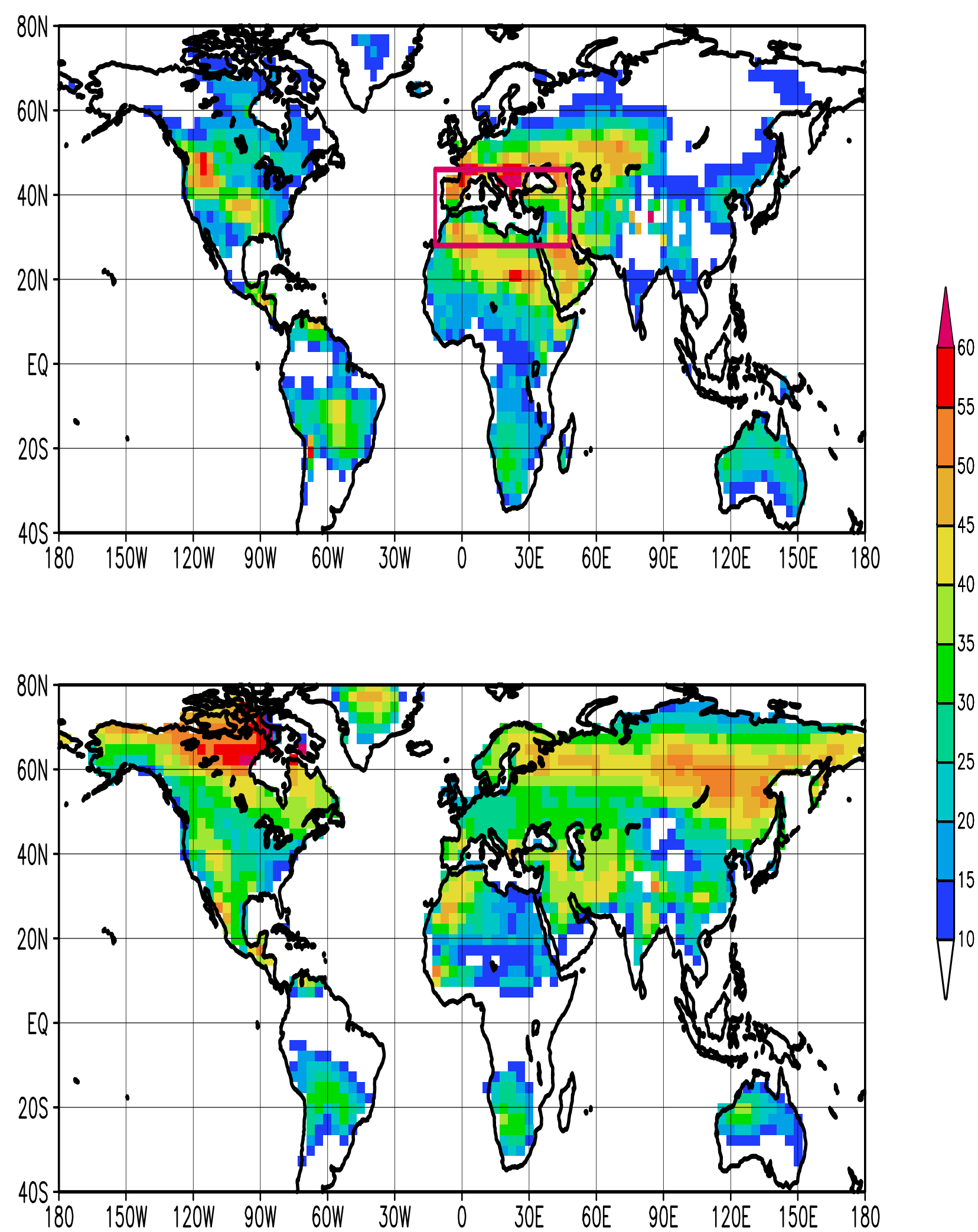

Figure 2: Same as figure 1 for maximum number of summer heat wave days. Limits of Mediterranean domain (top) has been reported. 


\section{pn10mm (DJF)}
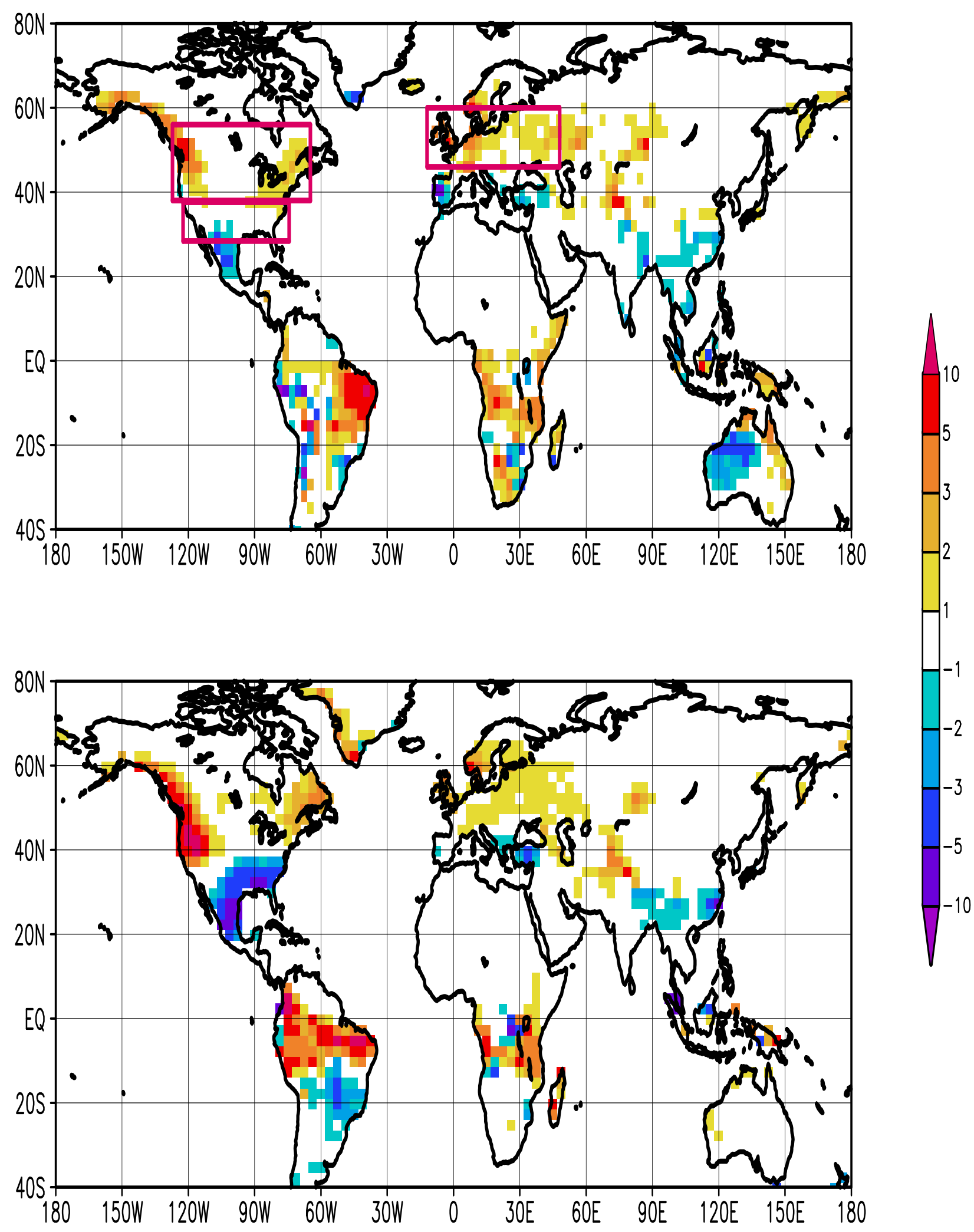

Figure 3: Same as figure 1 for number of winter days with precipitation exceeding $10 \mathrm{~mm}$. Limits of Canada, Usa and Europe domains (top) have been reported. 


\section{pxcdd (JUA)}
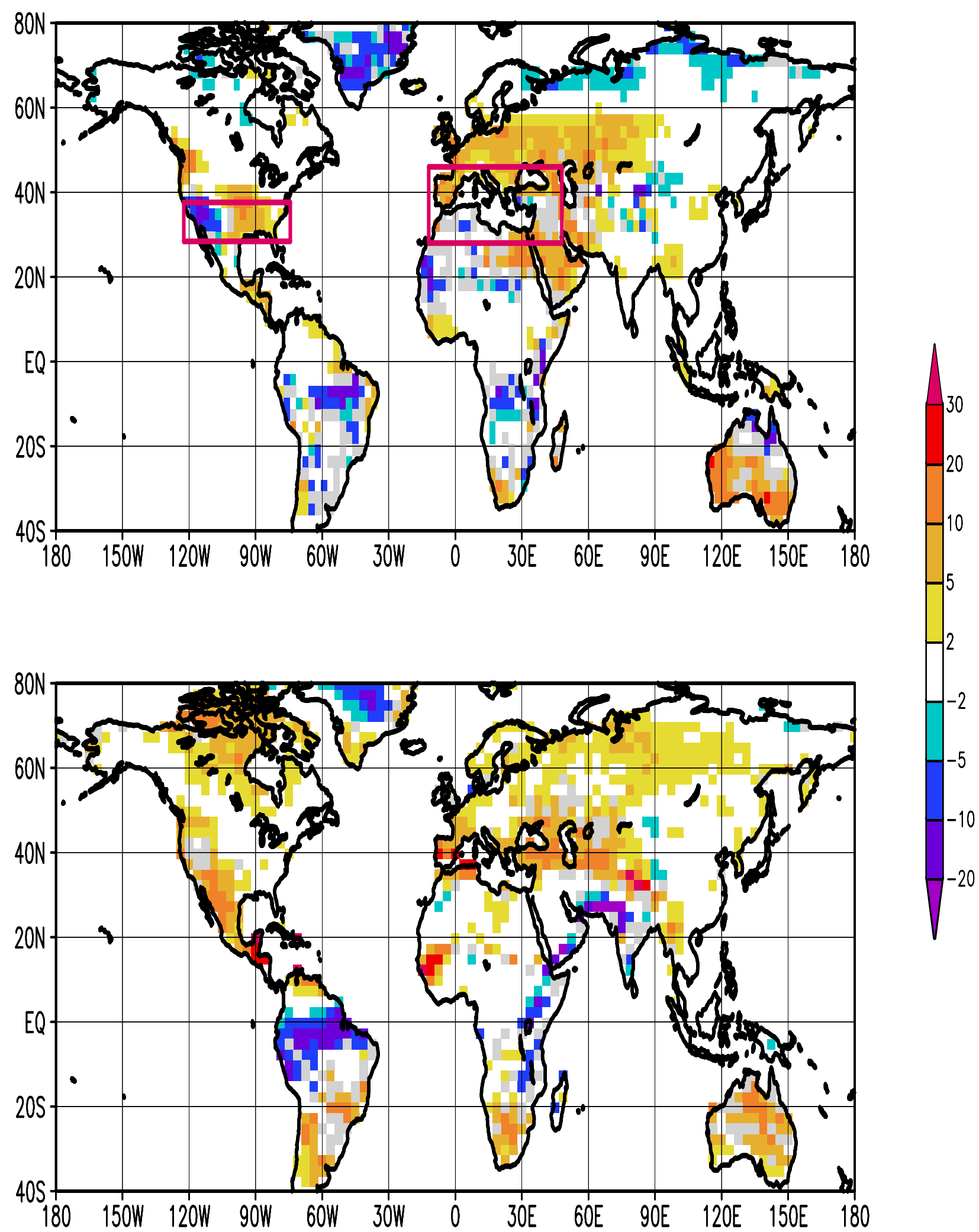

Figure 4: Same as figure 1 for maximum number of summer consecutive days with precipitation less than $1 \mathrm{~mm}$. Limits of USA and Mediterranean domains (top) have been reported. 
alaska

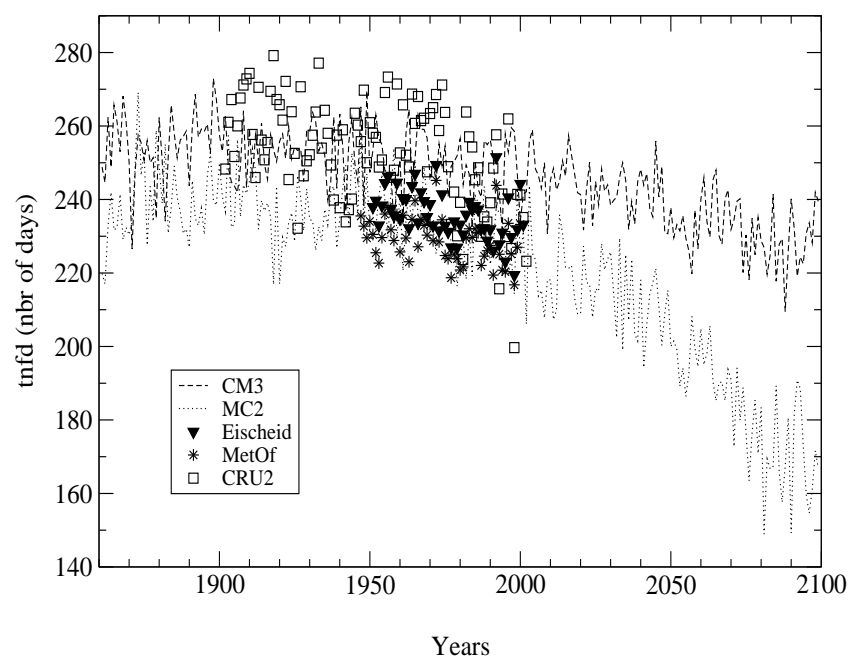

usa

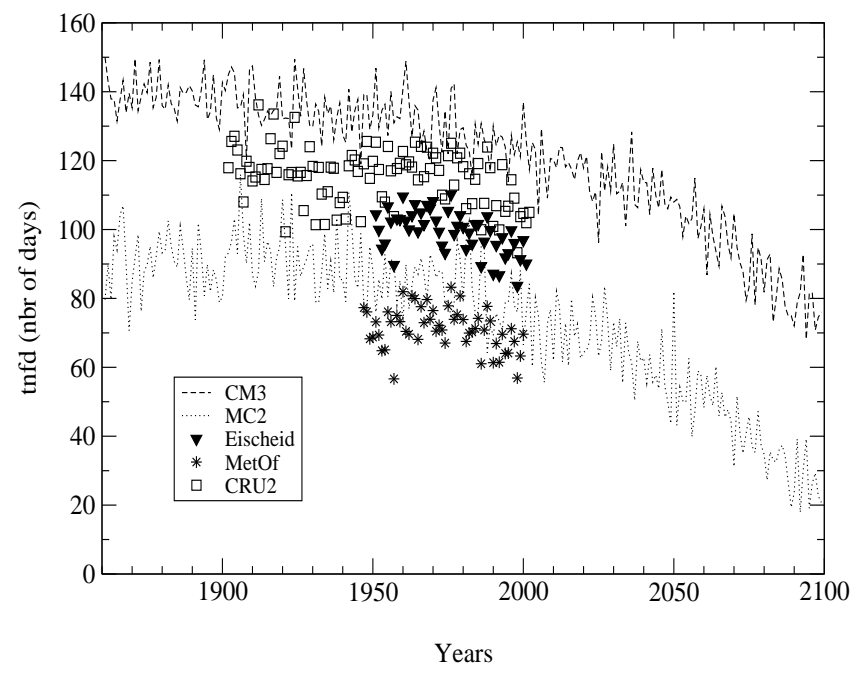

europ

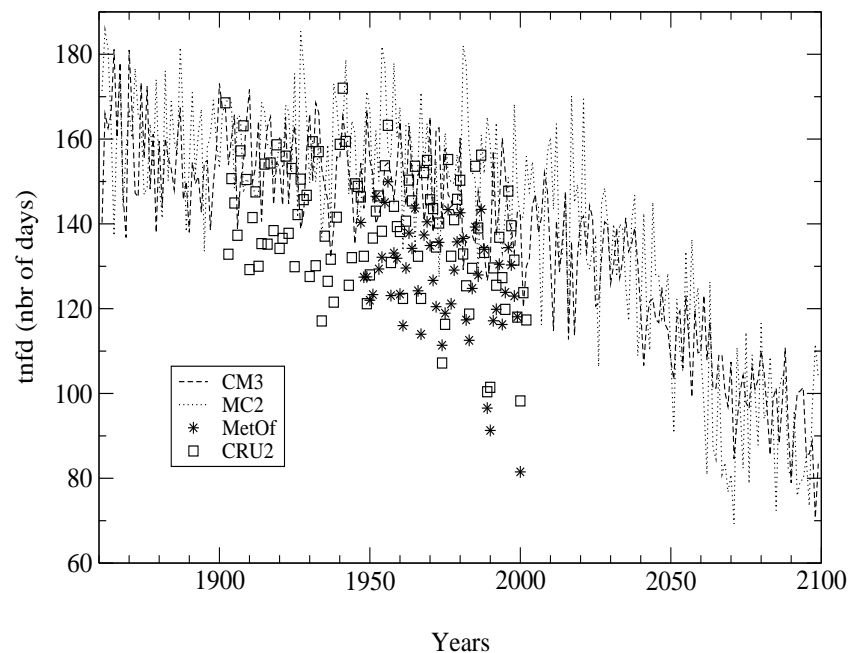

canada

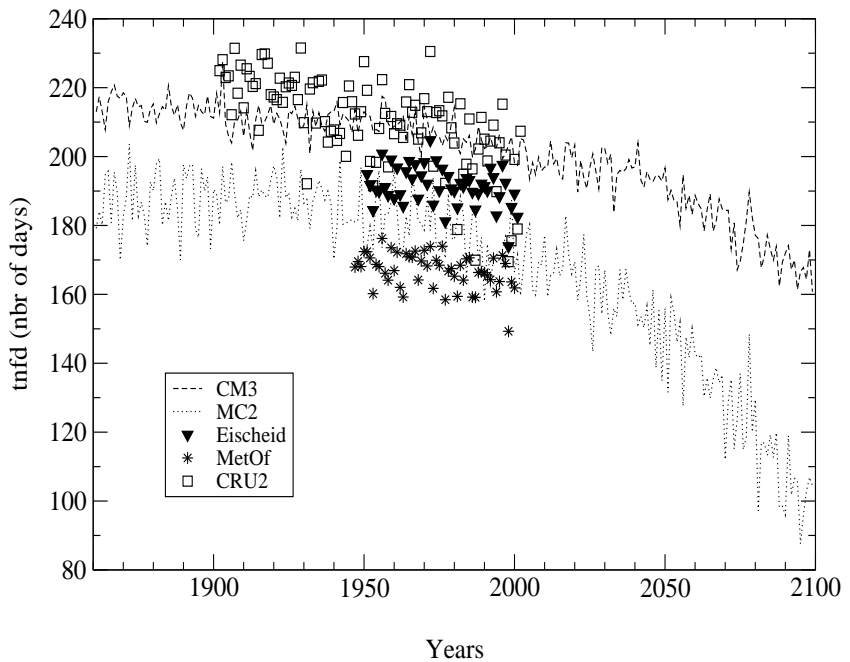


alaska

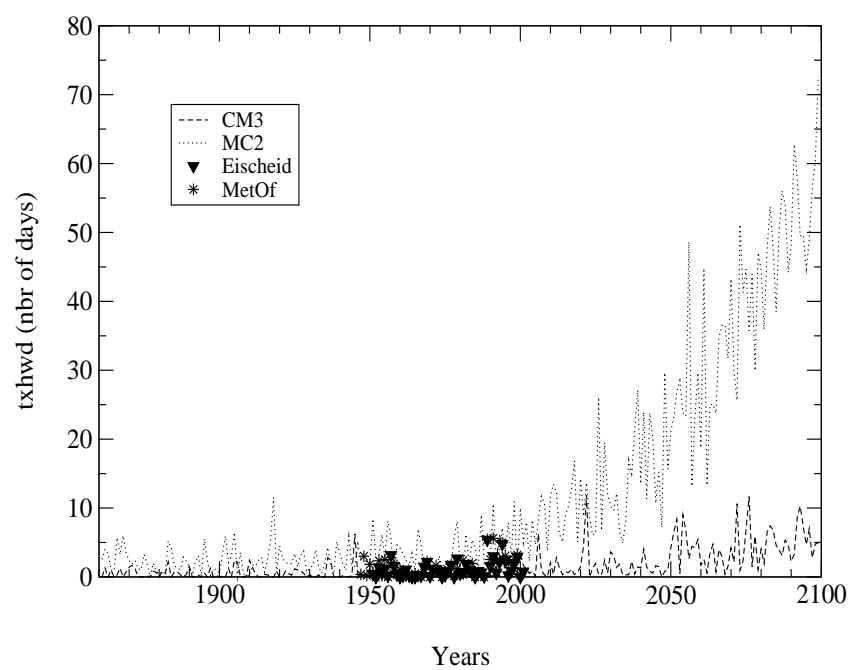

usa

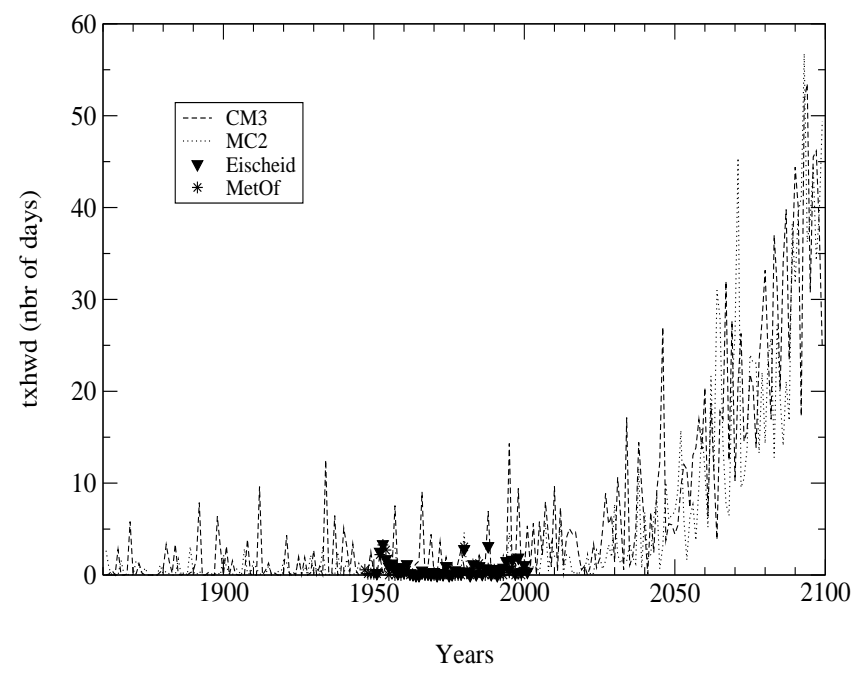

europ

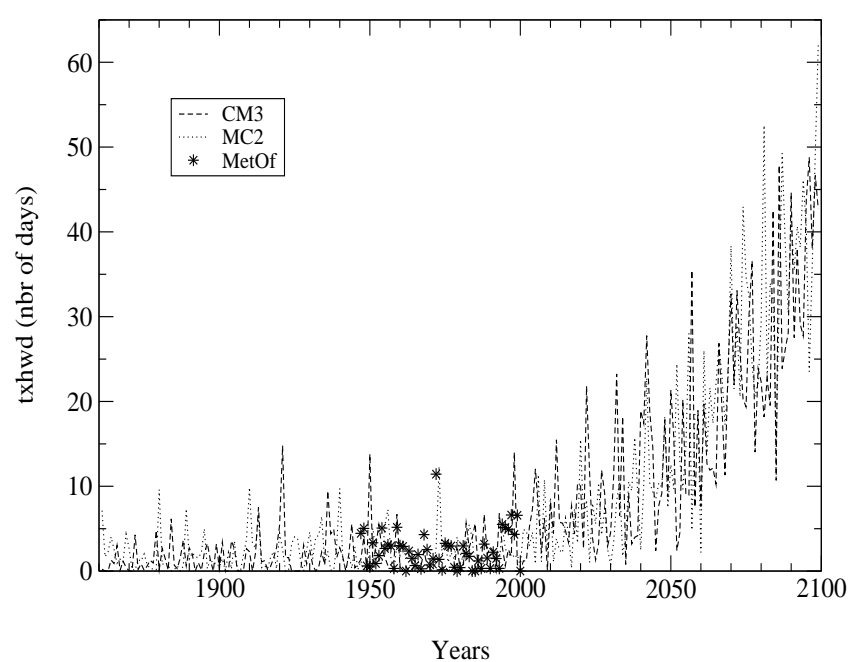

canada

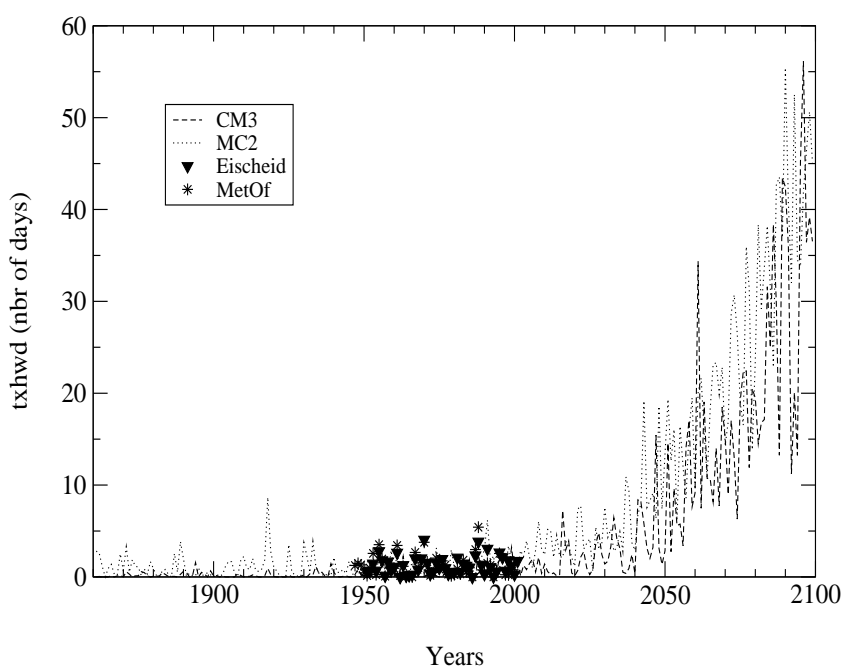

medit

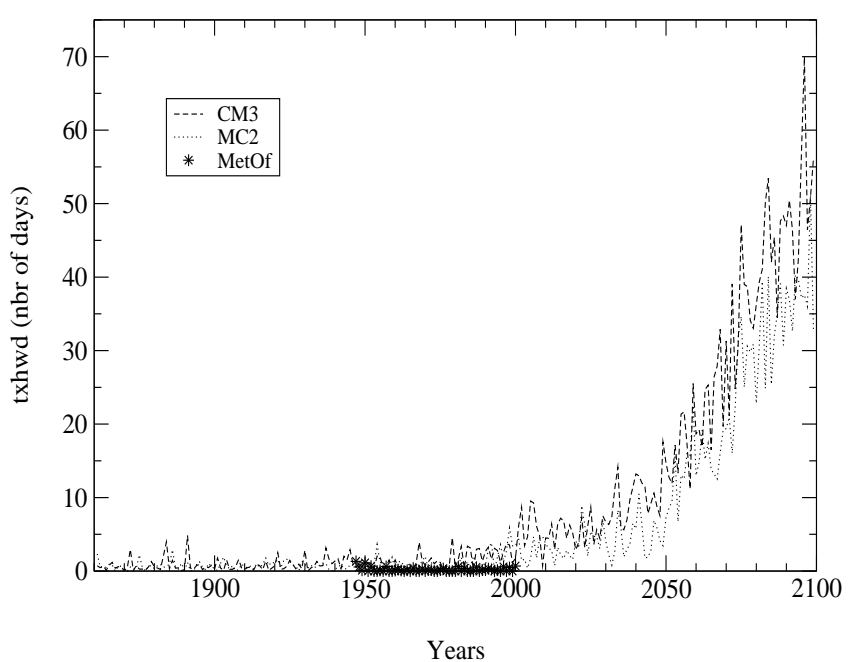

Figure 6: Same as figure 5 for maximum number of summer heat wave days. 
alaska

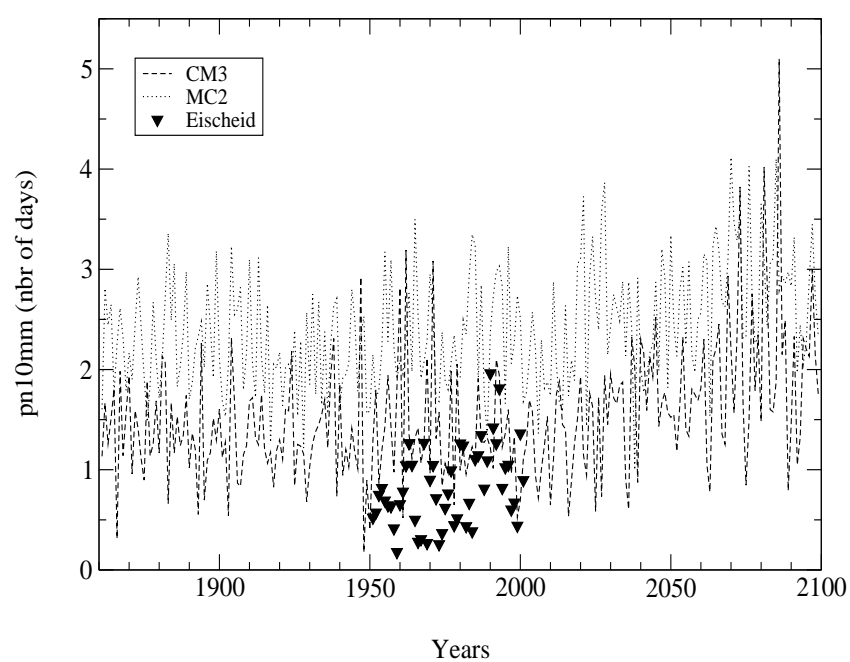

usa

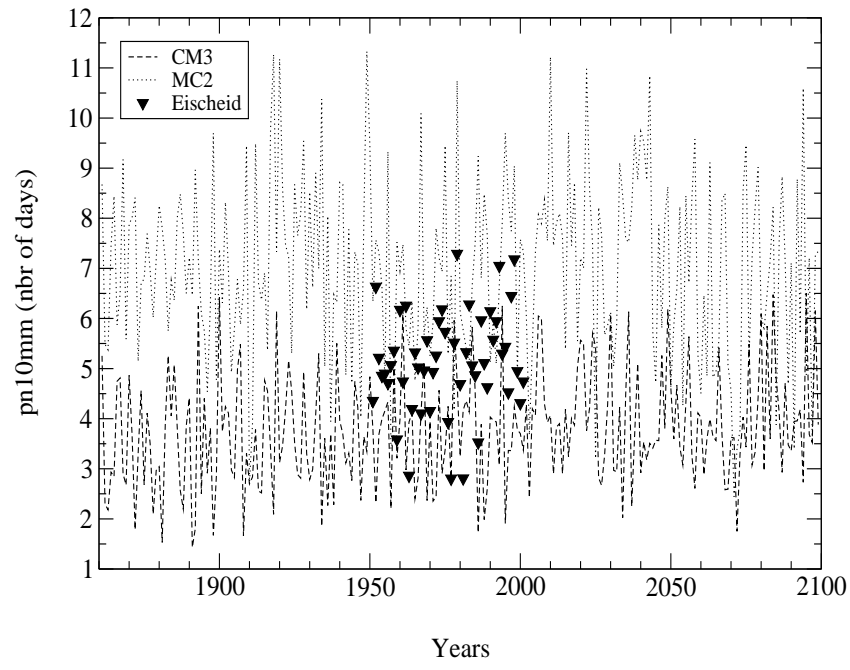

europ

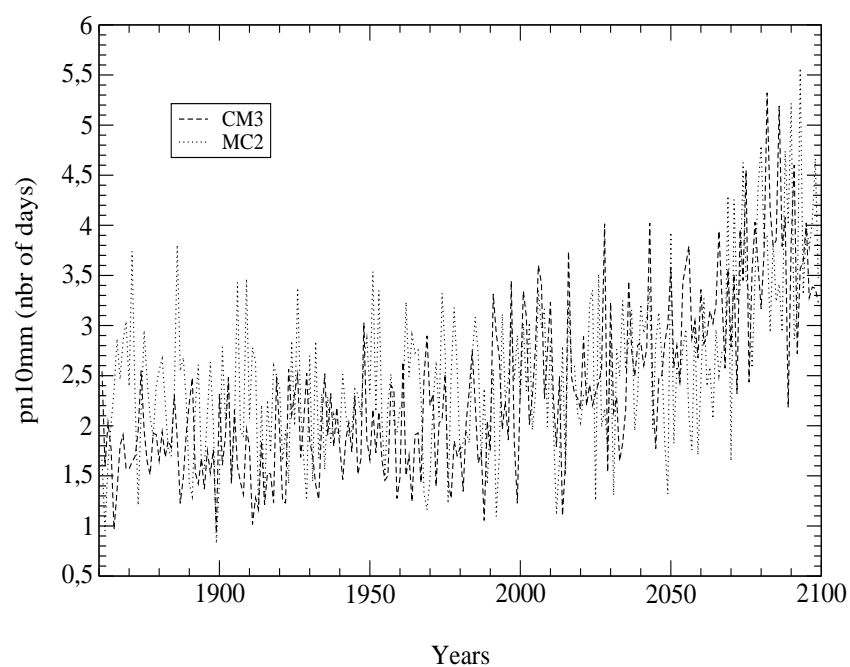

alaska

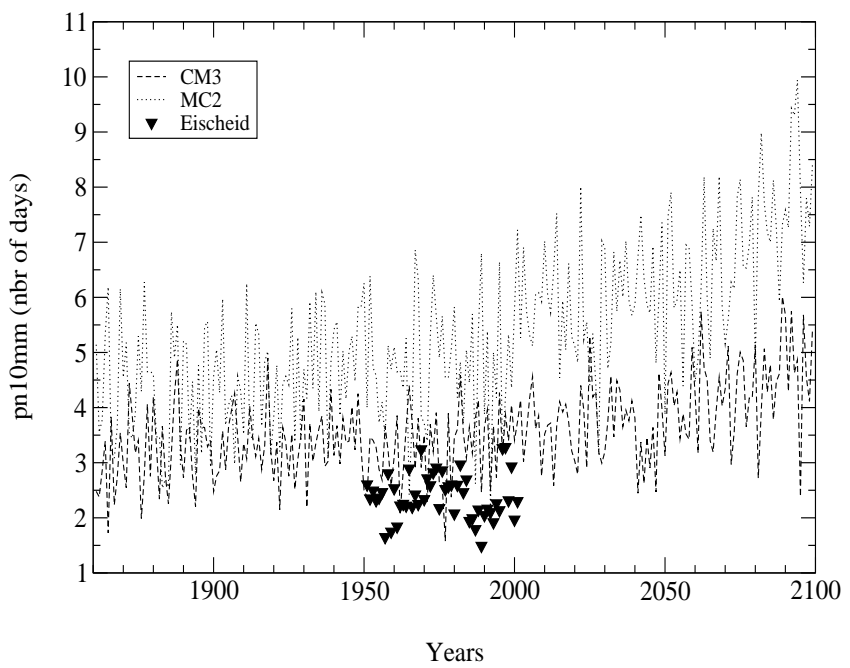

medit

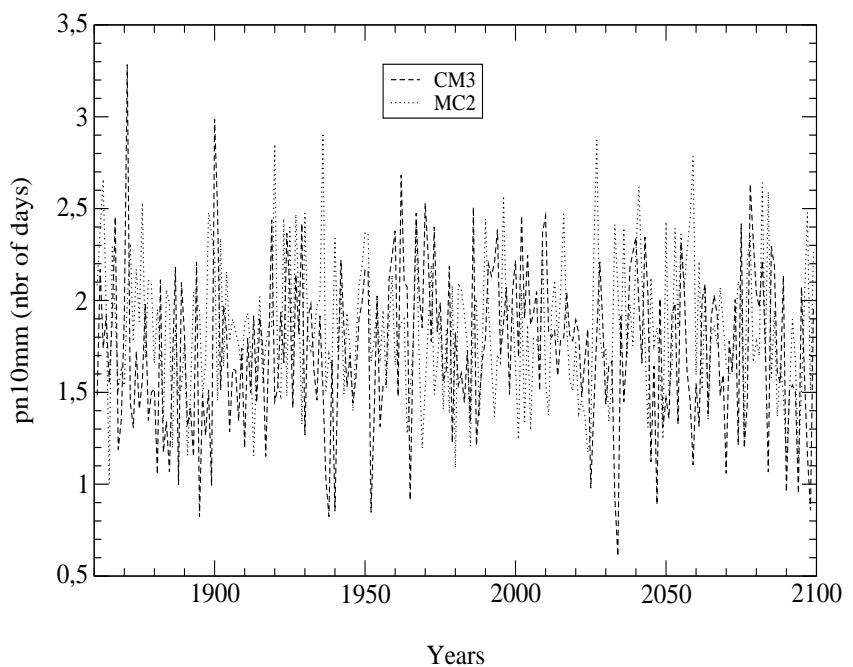

Figure 7: Same as figure 5 for number of winter days with precipitation exceeding $10 \mathrm{~mm}$. 
alaska

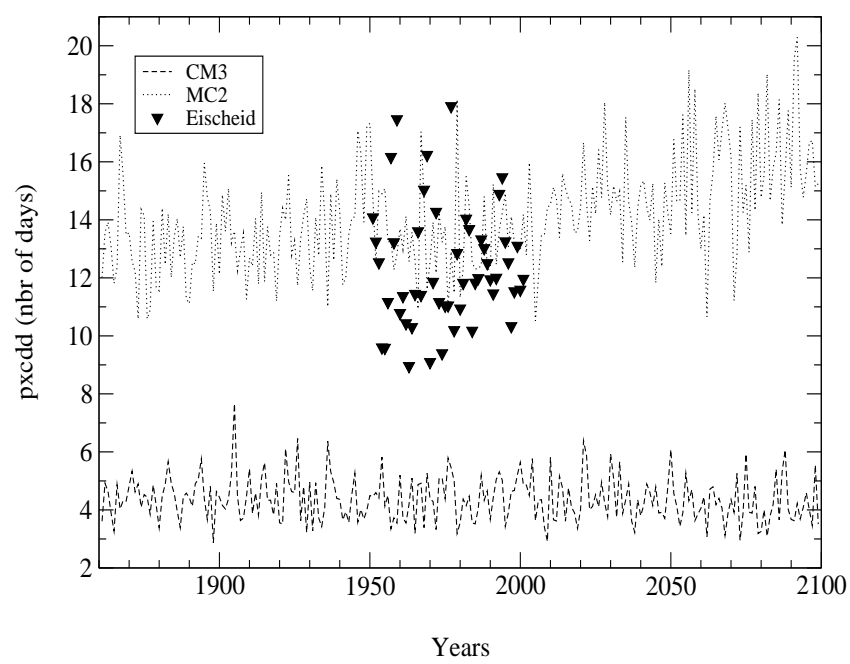

usa

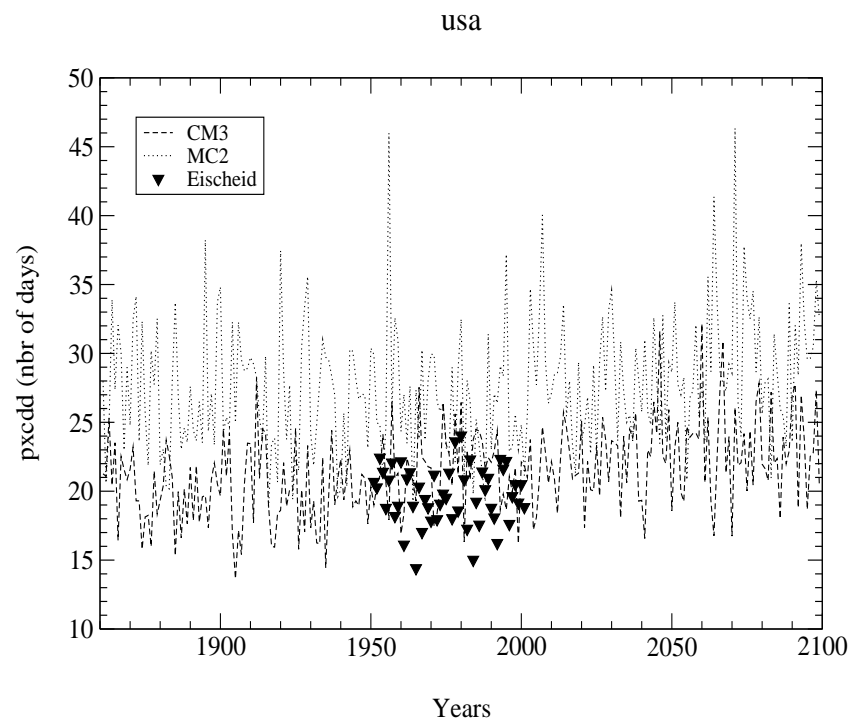

europ

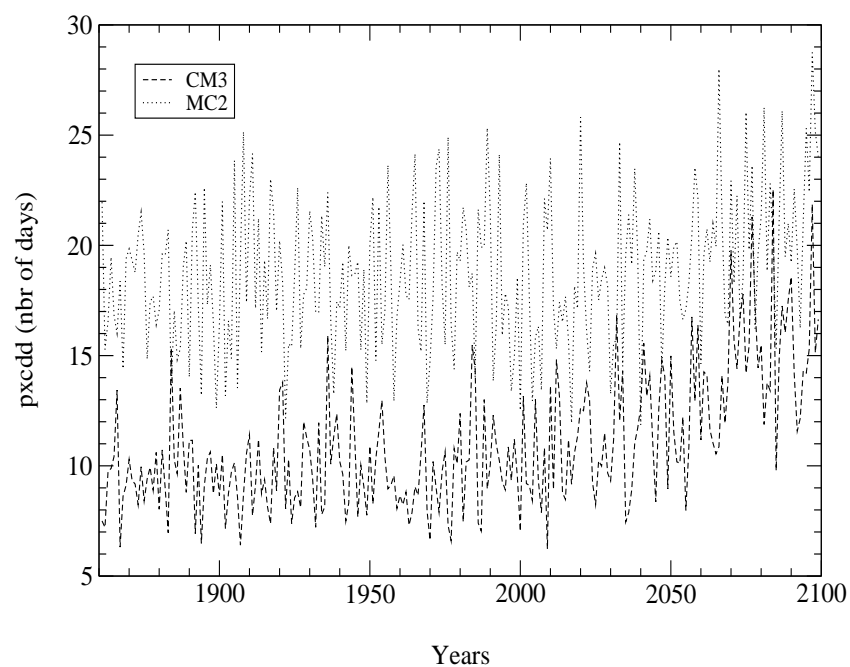

canada

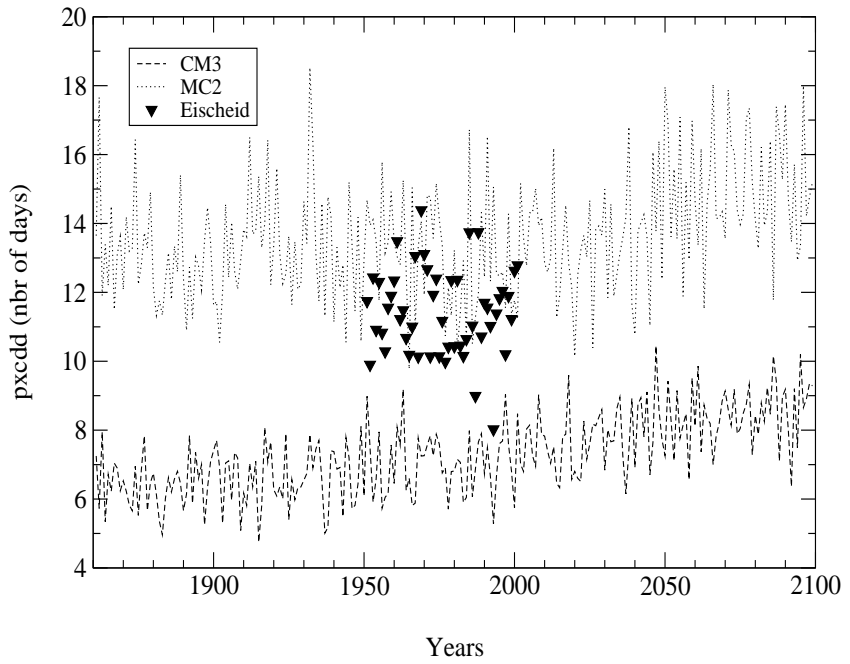

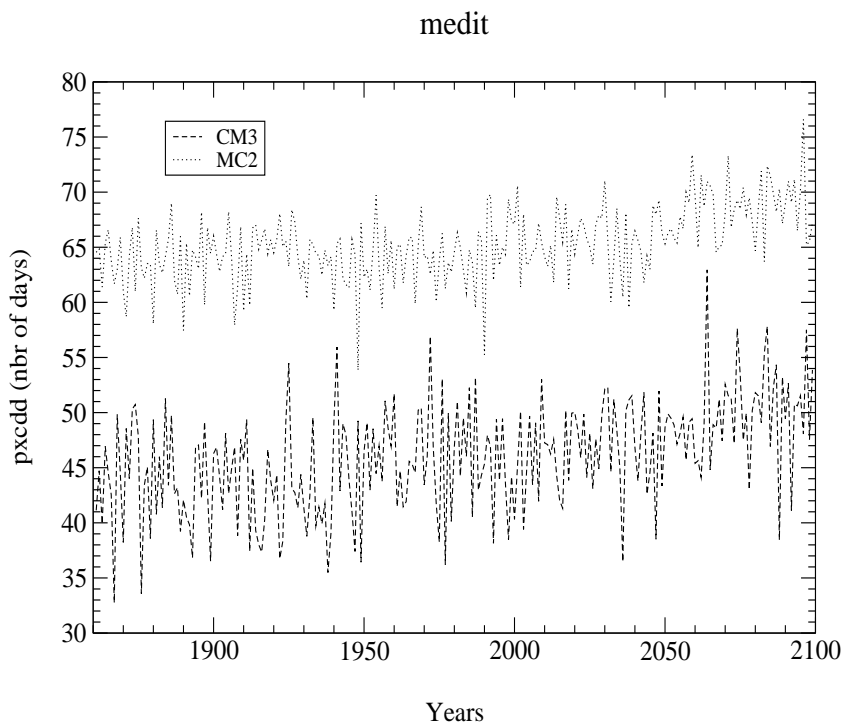

Figure 8: Same as figure 5 for maximum number of summer consecutive dry days. 
PXCDD (summer) for Europ

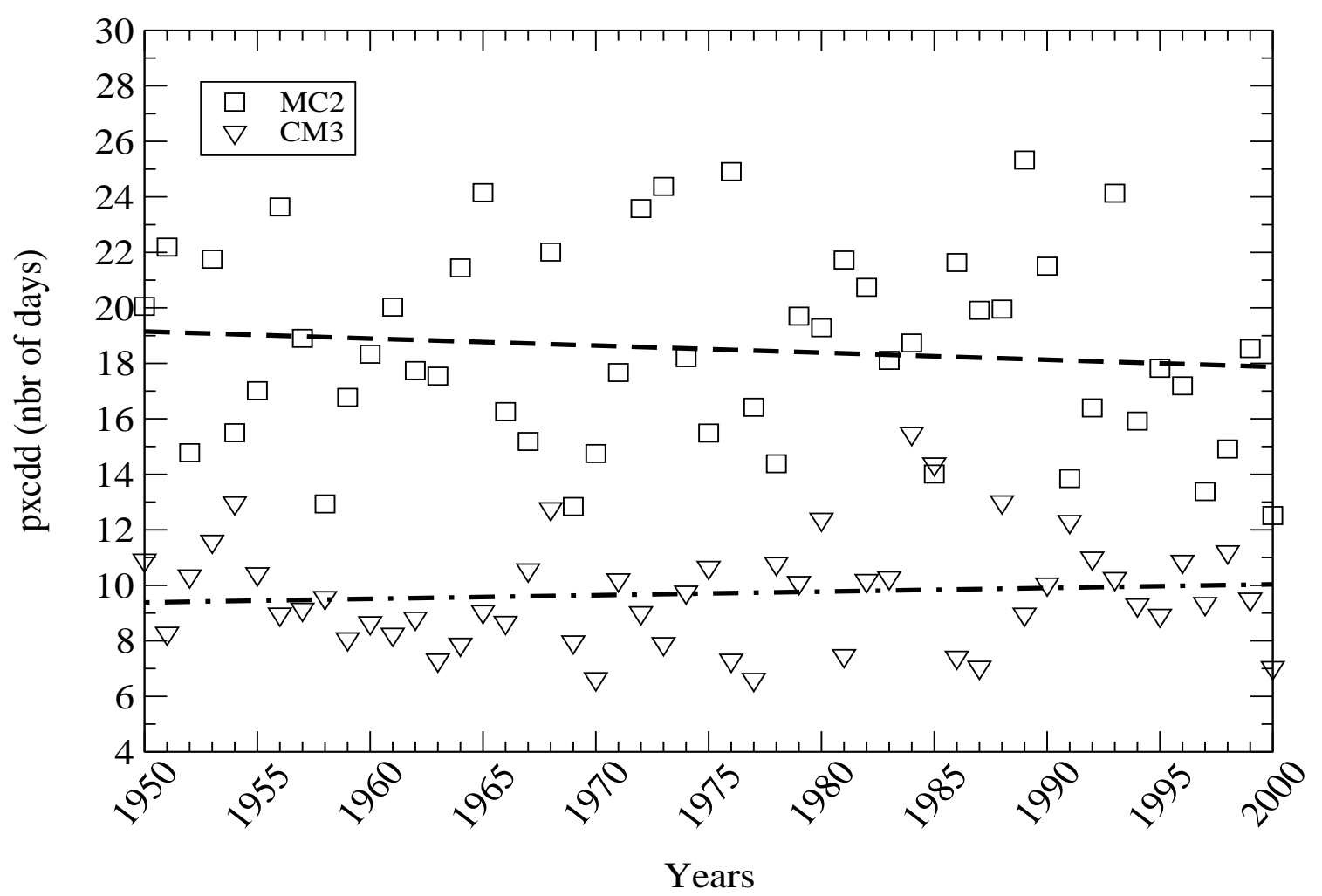

PXCDD (summer) for USA

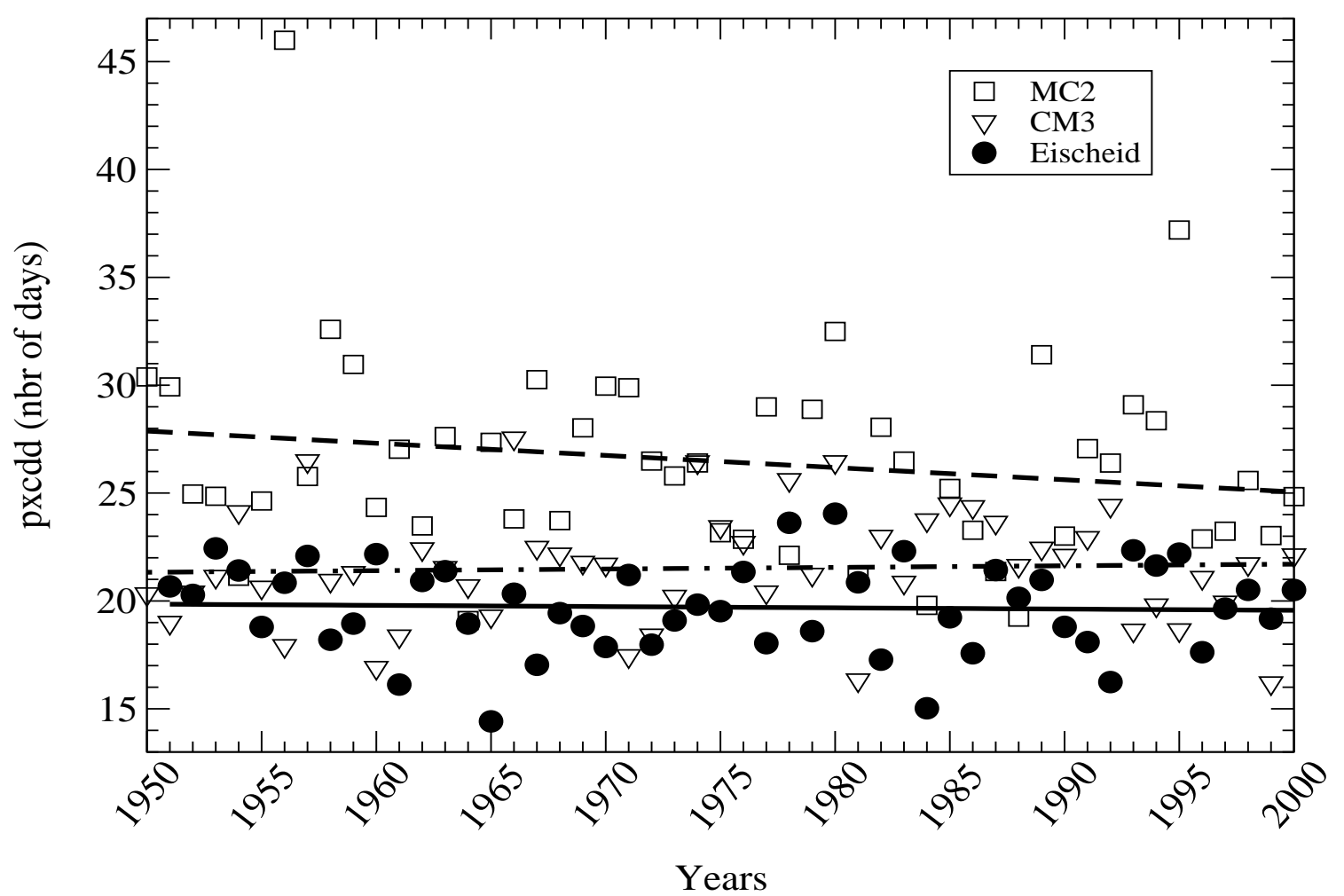

Figure 9: Evolution of maximum number of summer consecutive days with precipitation less than $1 \mathrm{~mm}$ over Europe (top) and USA (bottom). Horizontal axis represents the years 1950 to 2000. Vertical axis represents the number of days. MC2 is plotted as empty squares and regression line is dashed, CM3 is plotted as full circle and regression line is dash-dotted. Observations (Eischeid et al. 2000) are plotted as triangles and regression line is solid. 
alaska

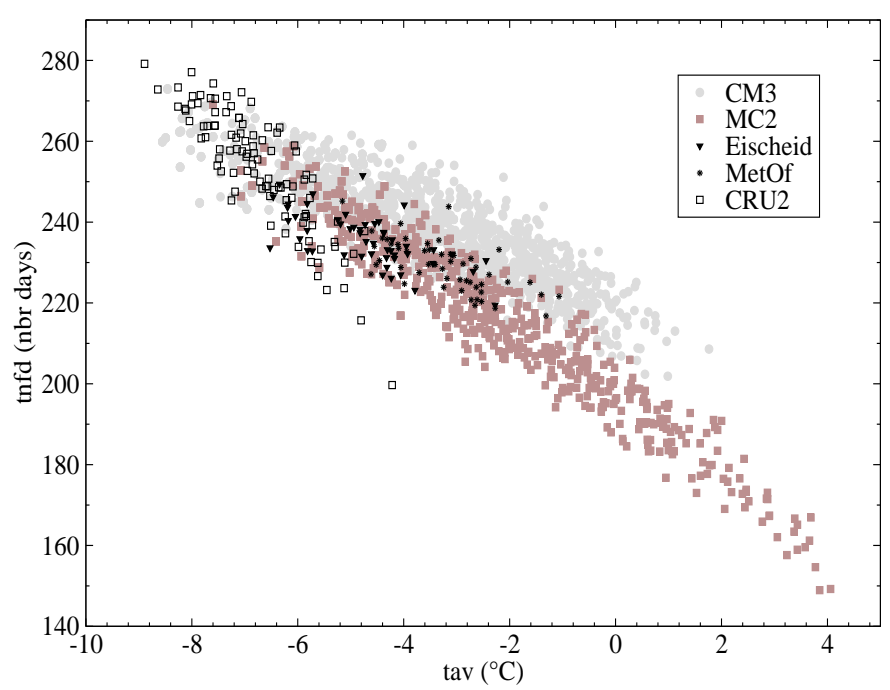

usa

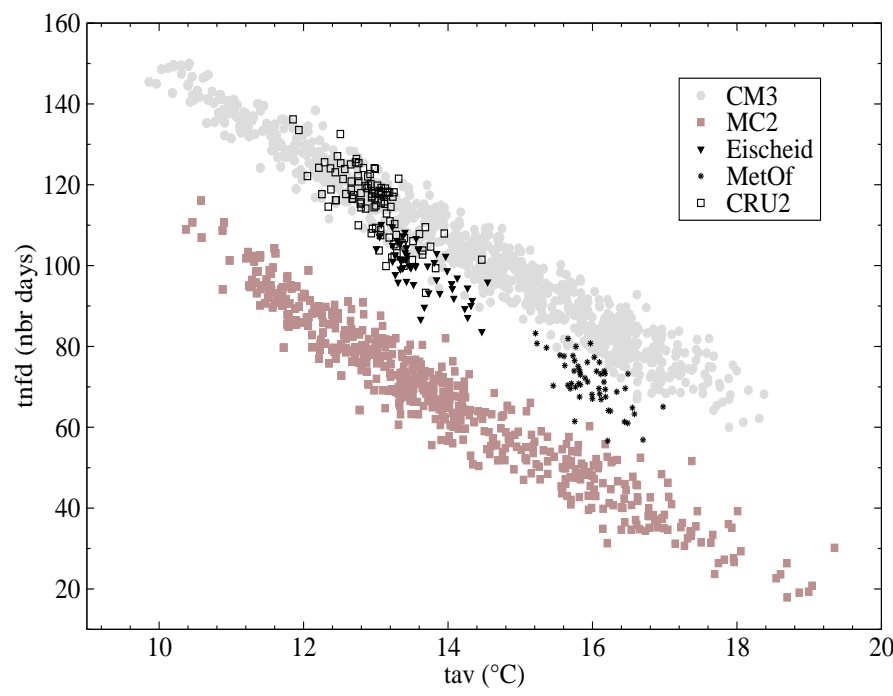

europ

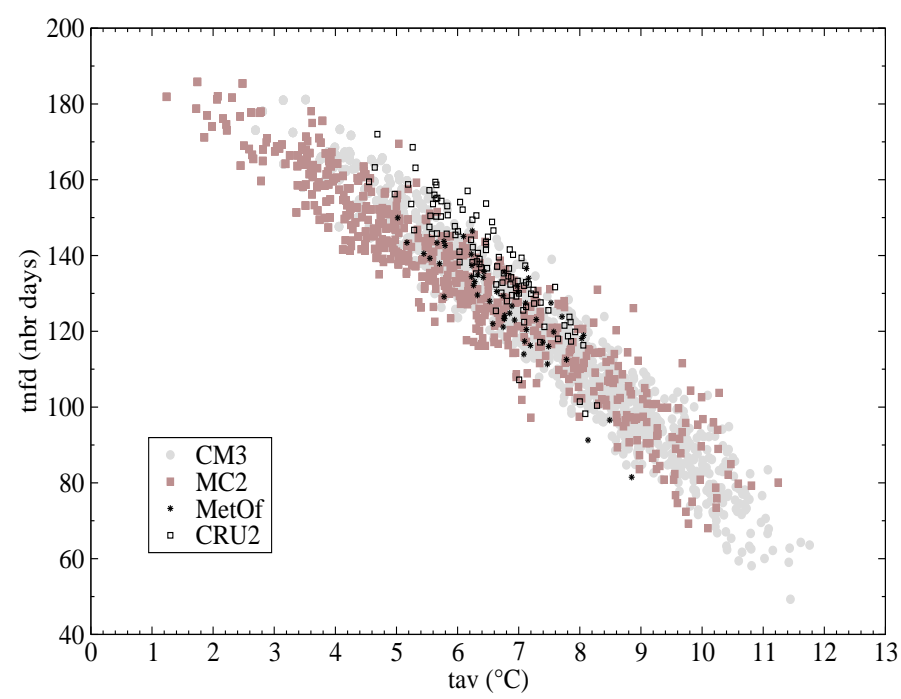

canada

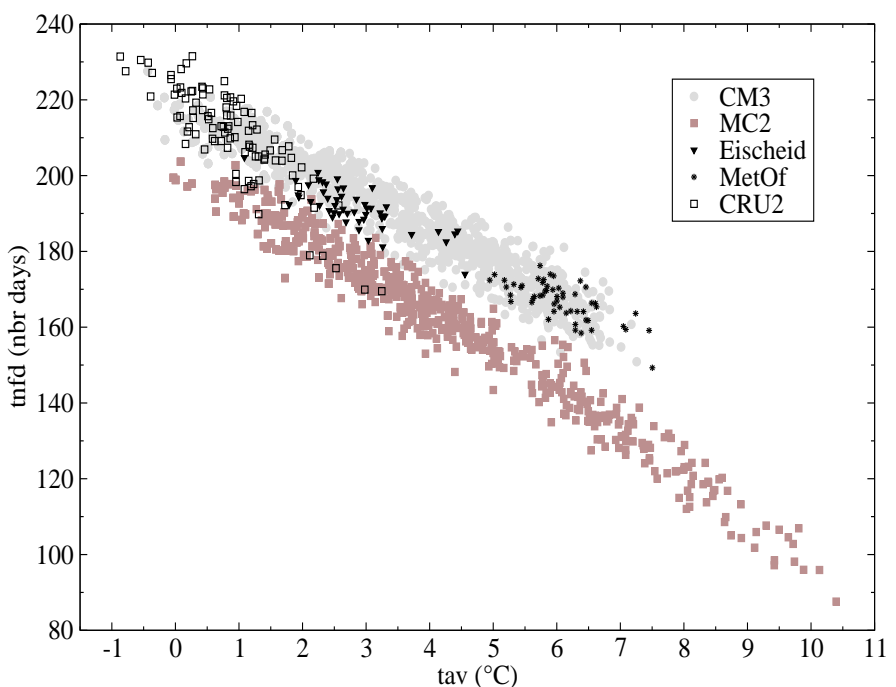

medit

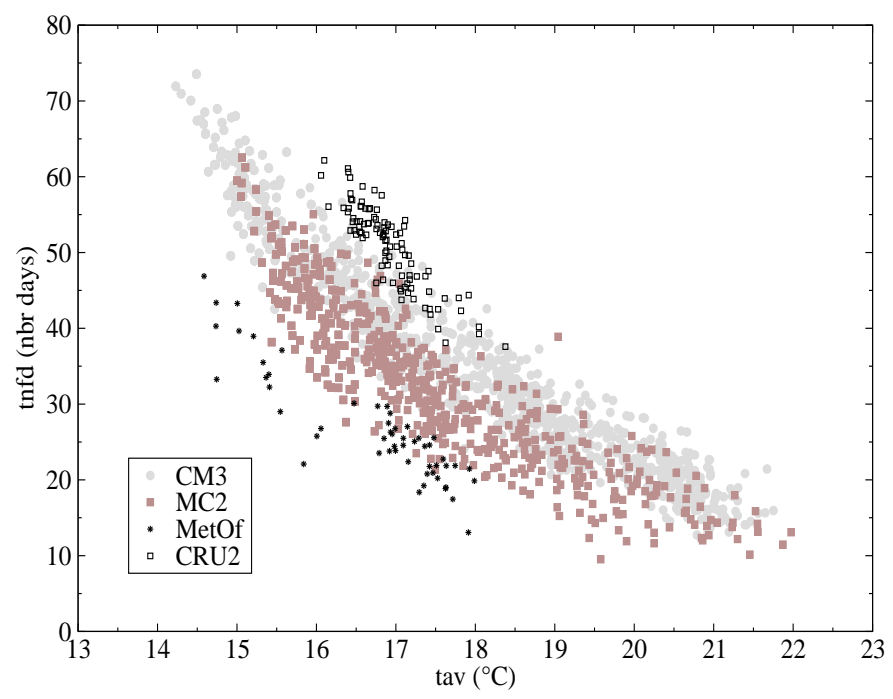

Figure 10: Sensitivity of annual number of frost days to mean annual temperature for Alaska (top left), Canada (top right), USA (middle left), Europe (bottom left) and Mediterranean countries (bottom right). Horizontal axis represents the mean annual temperature in ${ }^{\circ} \mathrm{C}$. Vertical axis represents the number of days. Observations are plotted as full triangles (Eischeid et al. 2000), stars (Caesar et al. 2005) or empty squares (New et al. 2000) and simulations for the $2 \mathrm{O}^{\text {th }}$ century and scenarios commit, B1, A1B and A2 are represented as full grey circles (CM3) and brown full squares (MC2). 
alaska

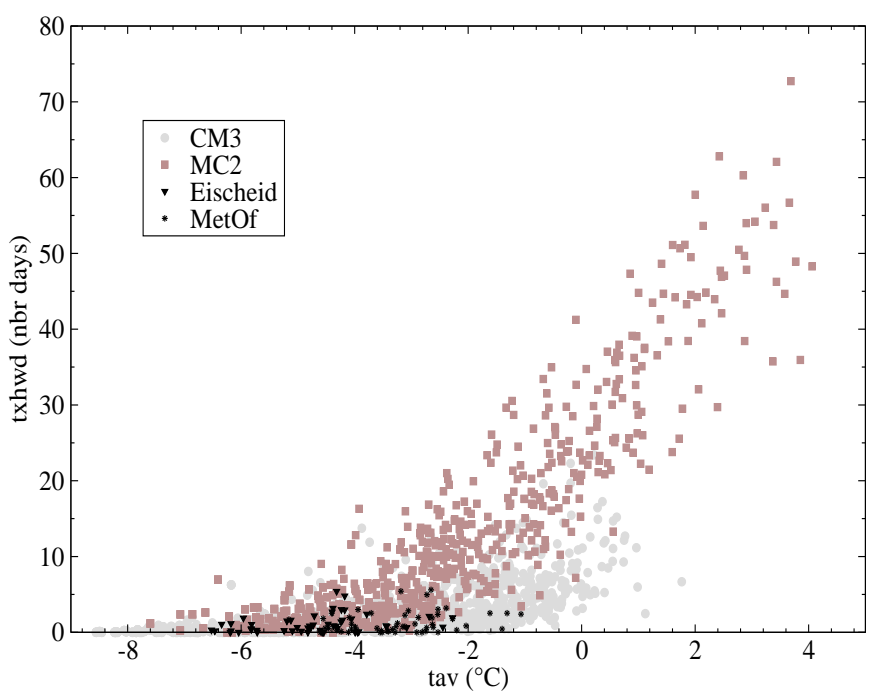

usa

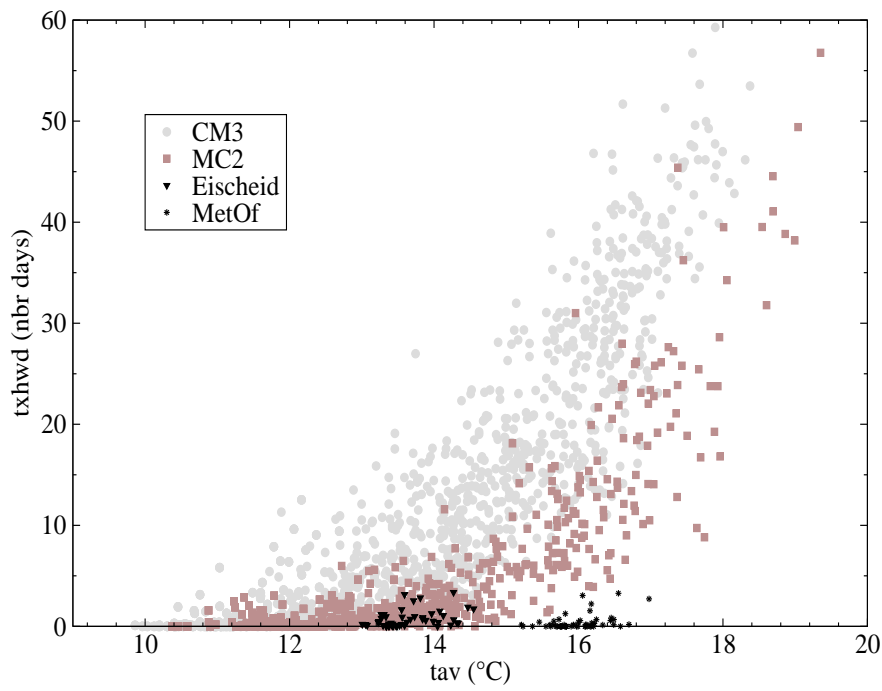

Index txhwd: CNRM-CM3 and IPSL-MC2 (1861-2299) europ

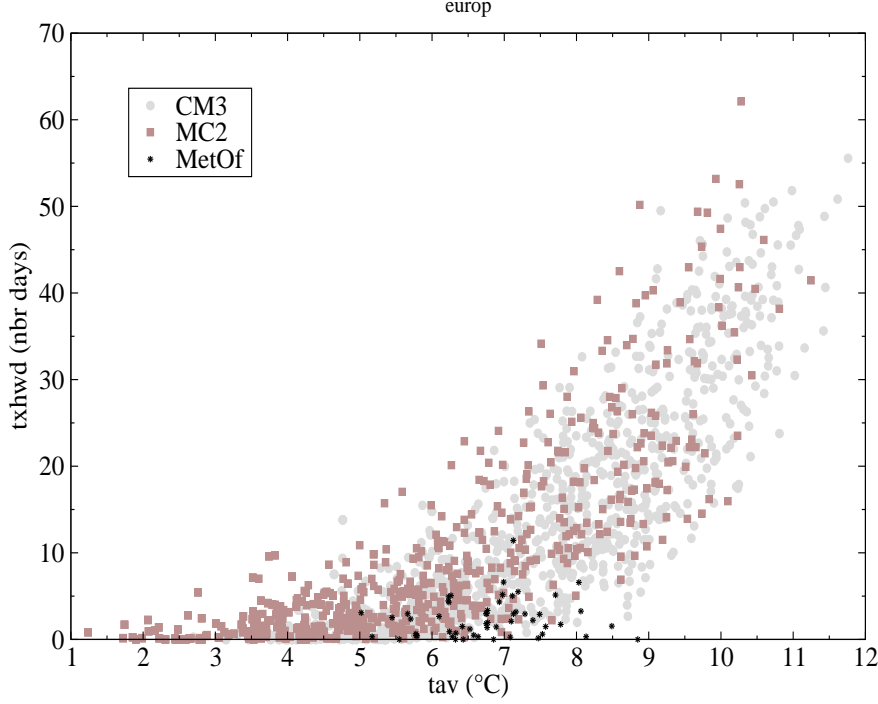

canada

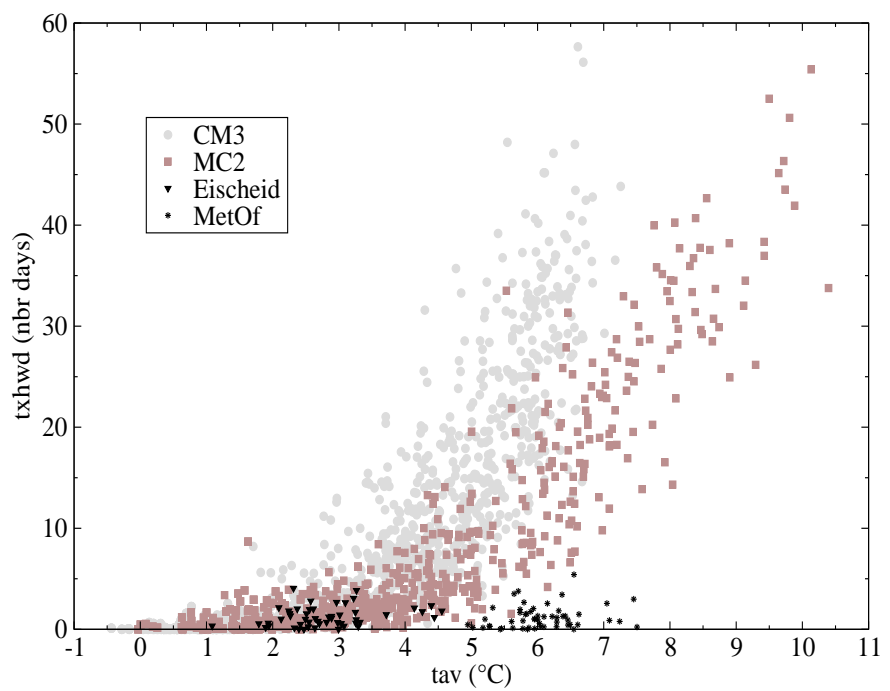

medit

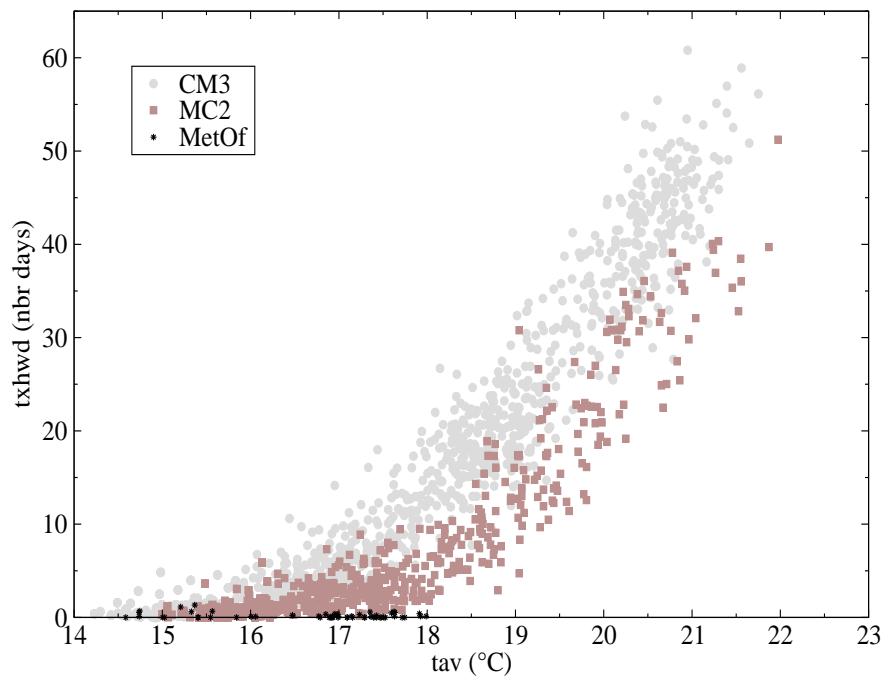

Figure 11: Same as figure 10 for maximum number of summer heat wave days. 
Index txq90: CNRM-CM3 and IPSL-MC2 (1861-2299)

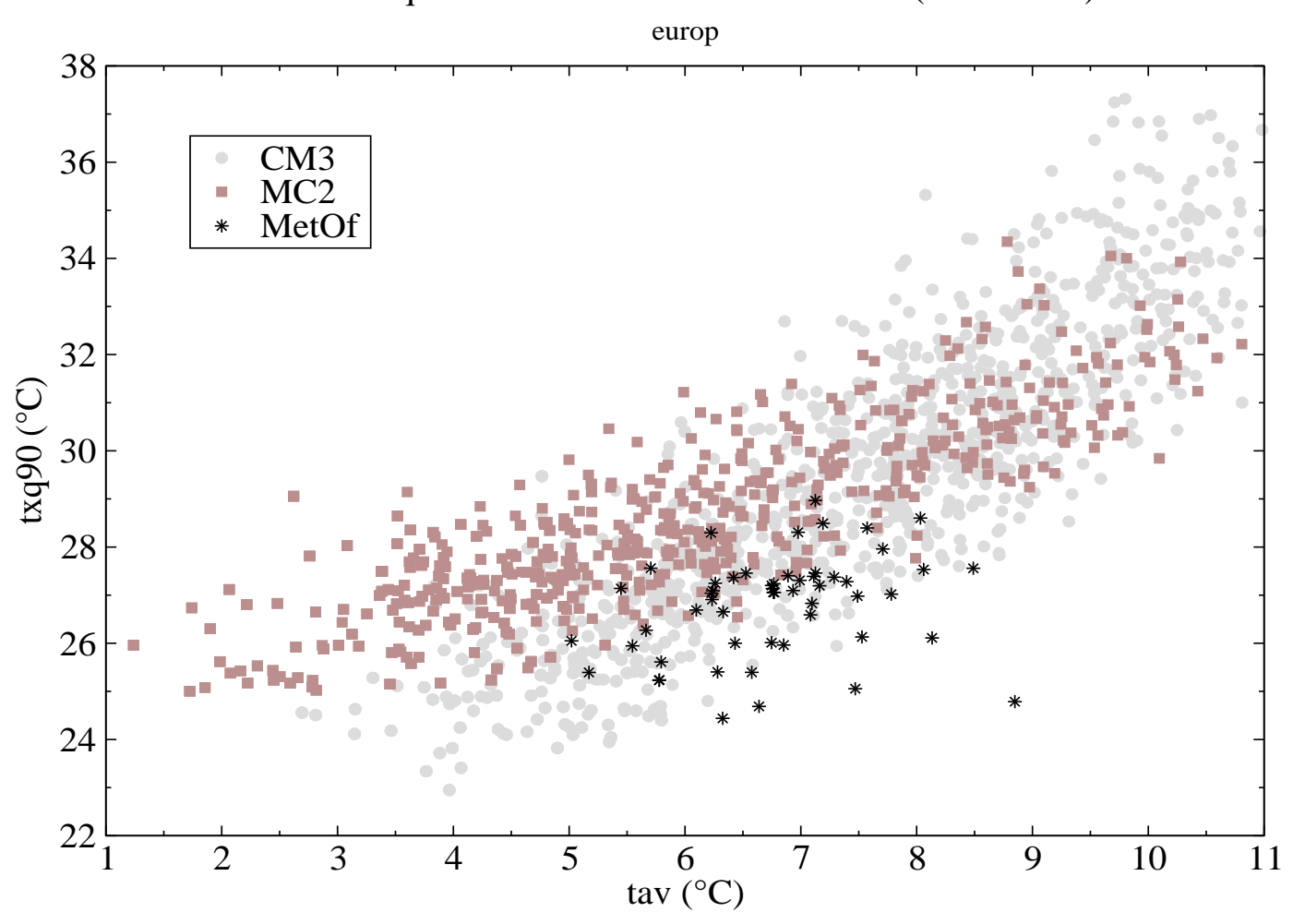

Index txq90: CNRM-CM3 and IPSL-MC2 (1861-2299)

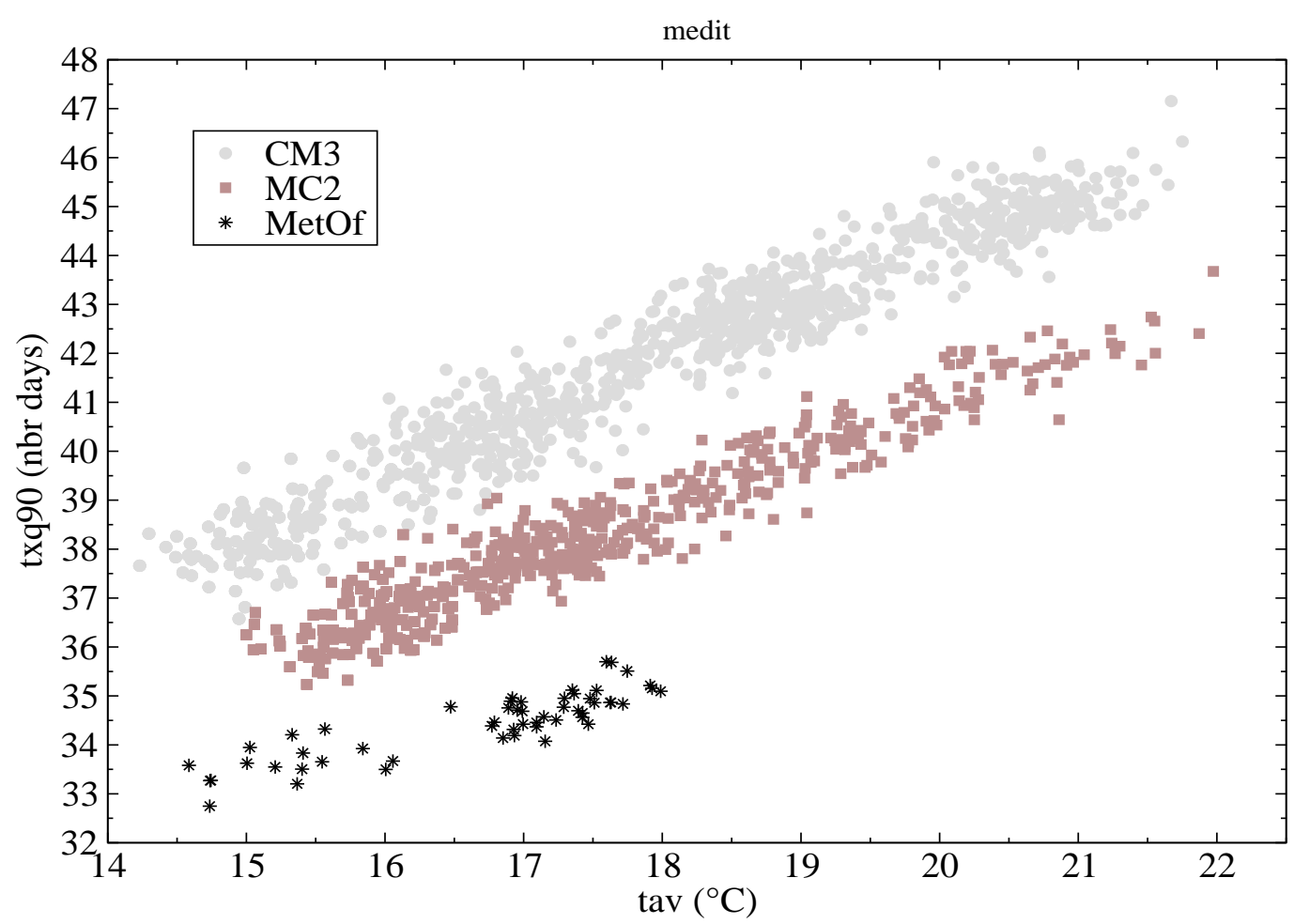

Figure 12: Same as figure 10 for $90^{\text {th }}$ percentile of $\mathrm{T}_{x}$ over Europe (top) and Mediterranean periphery (bottom). 
alaska

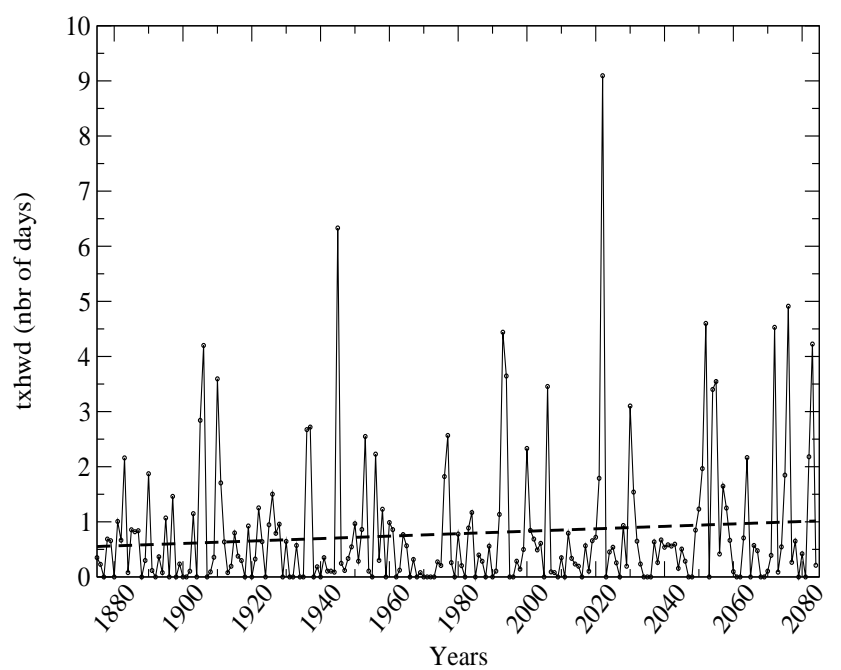

usa

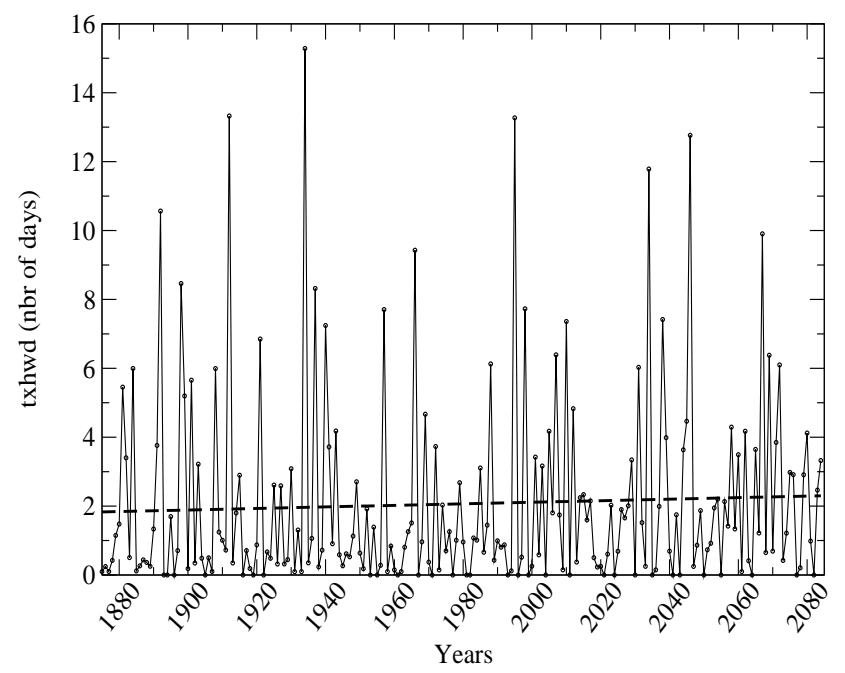

europ

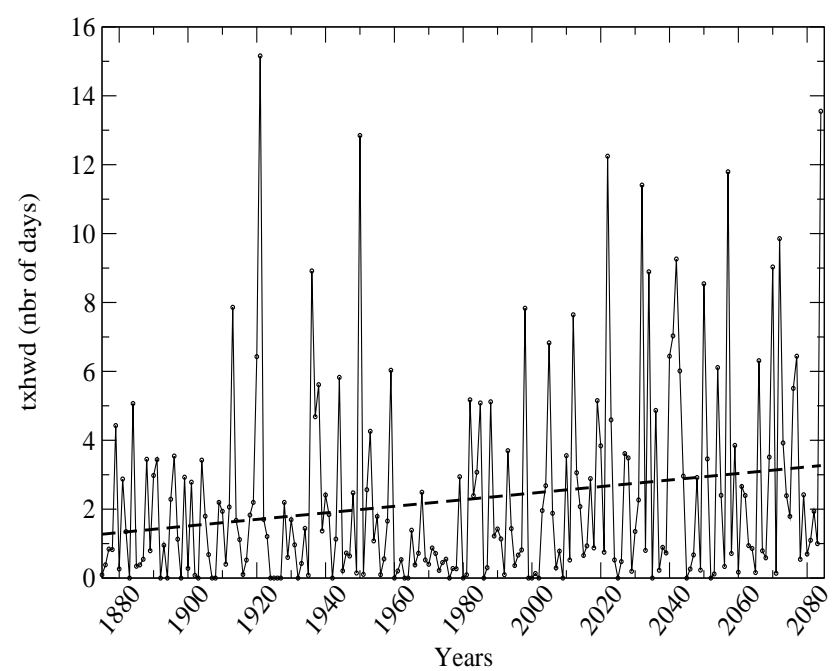

canada
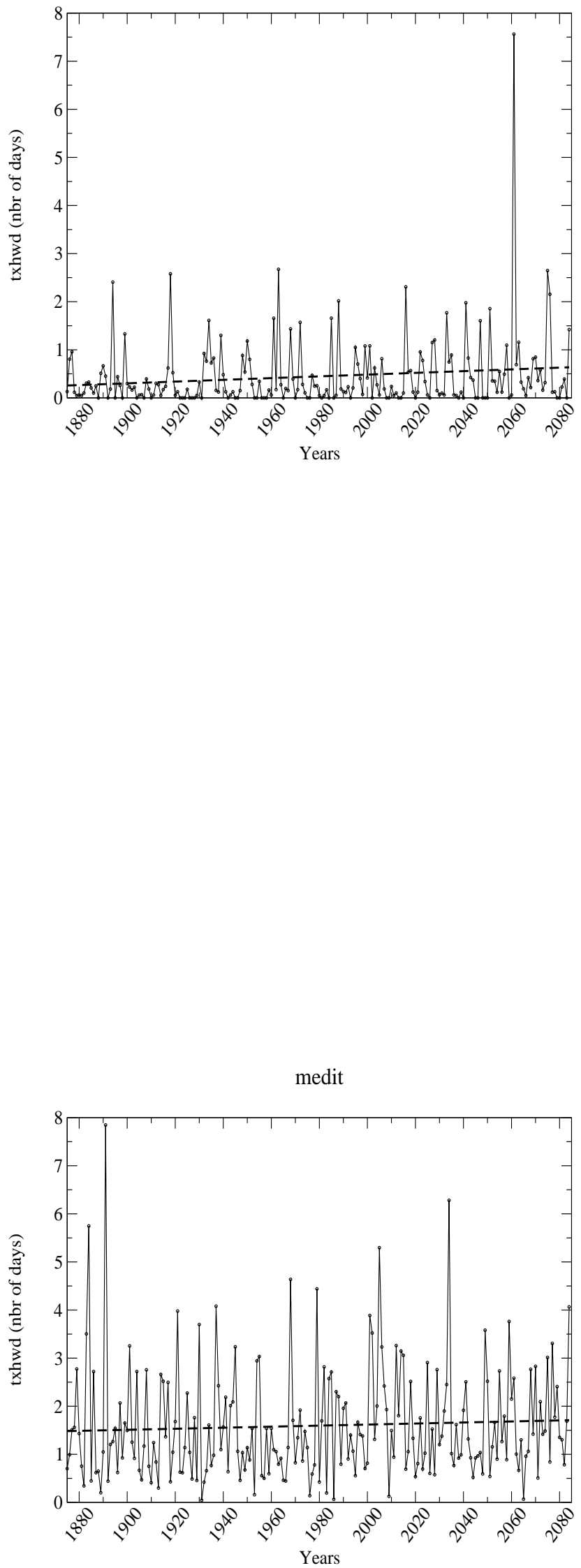

Figure 13: Same as figure 6 for maximum number of summer heat wave days calculated from yearly moving normals. 
alaska

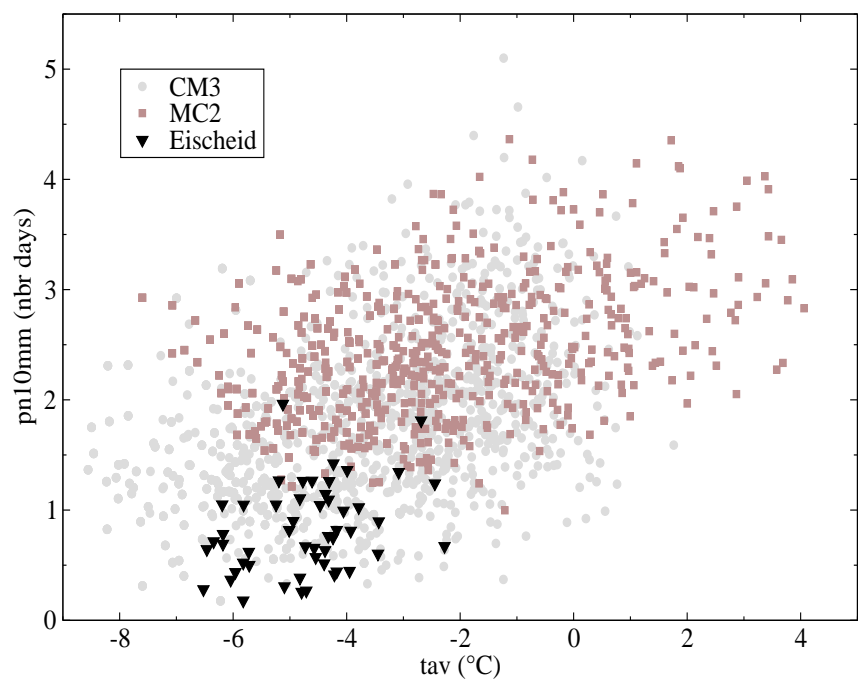

usa

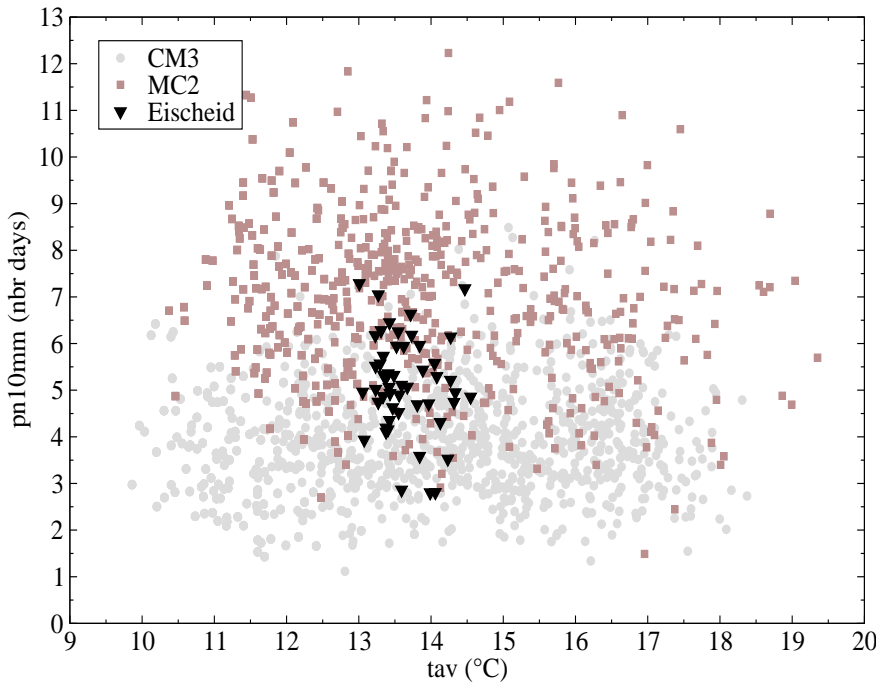

europ

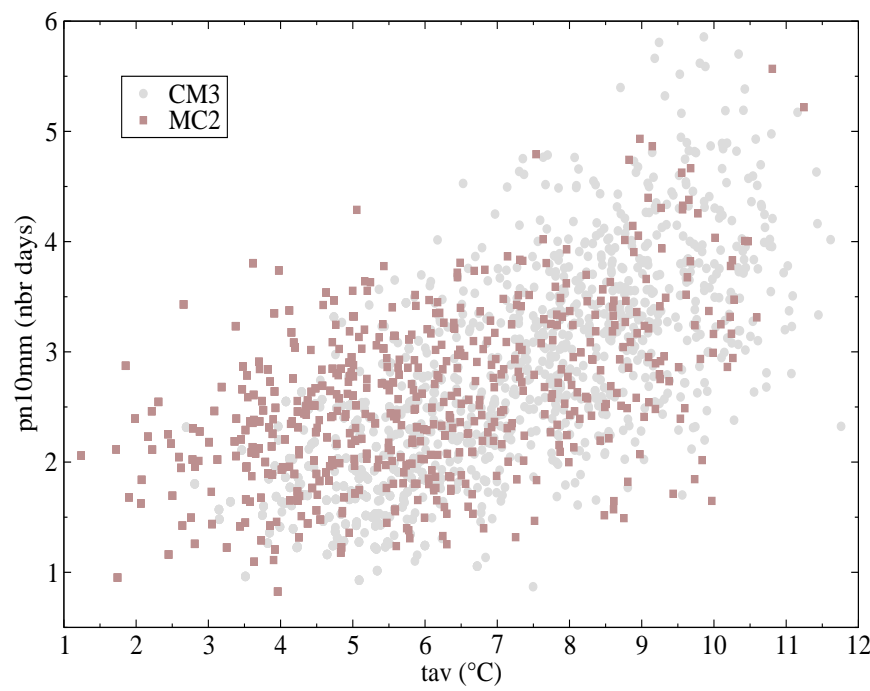

canada

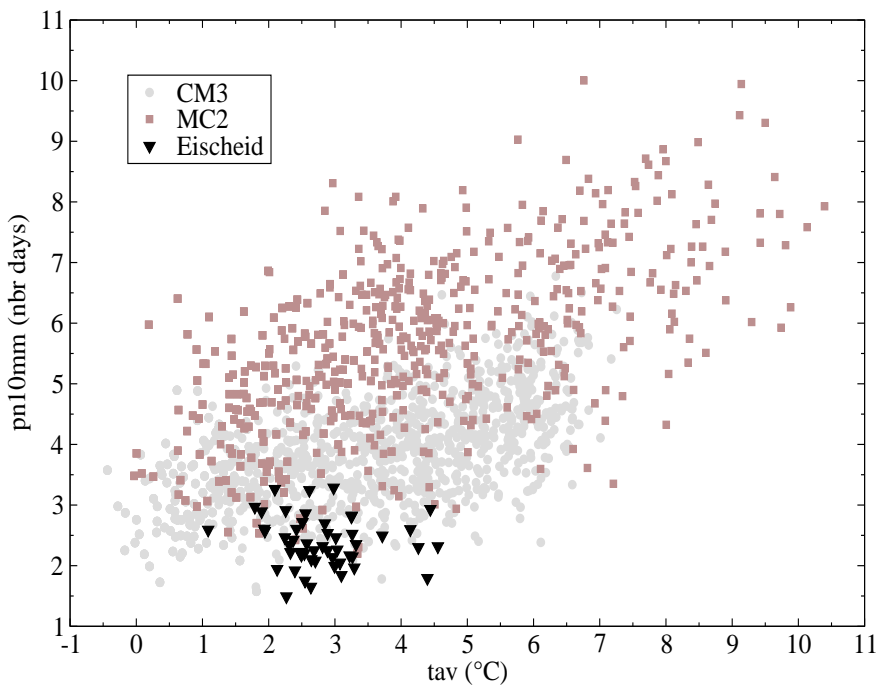$$
\text { tav }\left({ }^{\circ}\right)
$$

$$
\text { ) }
$$


alaska

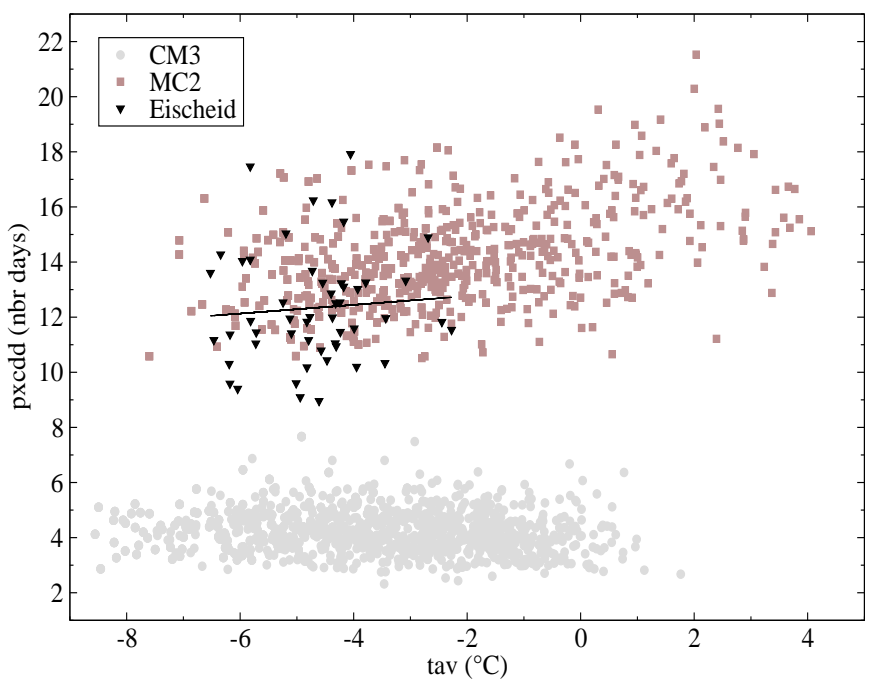

usa

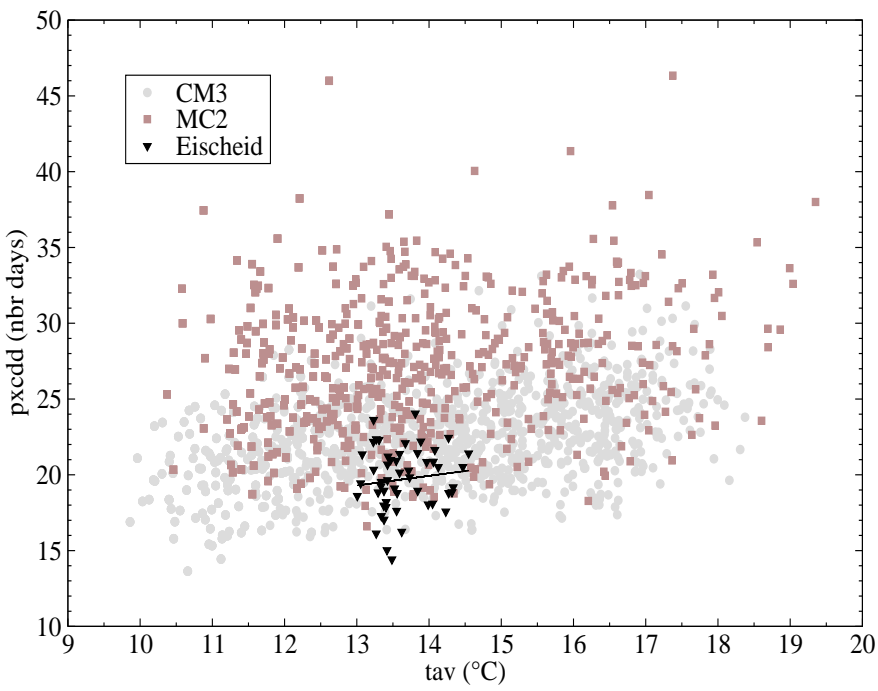

europ

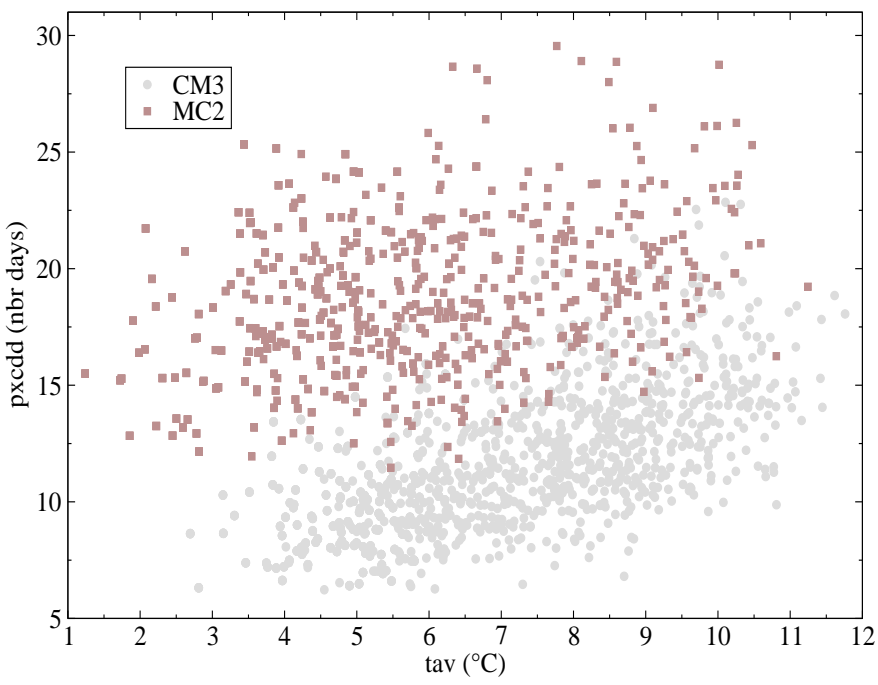

canada

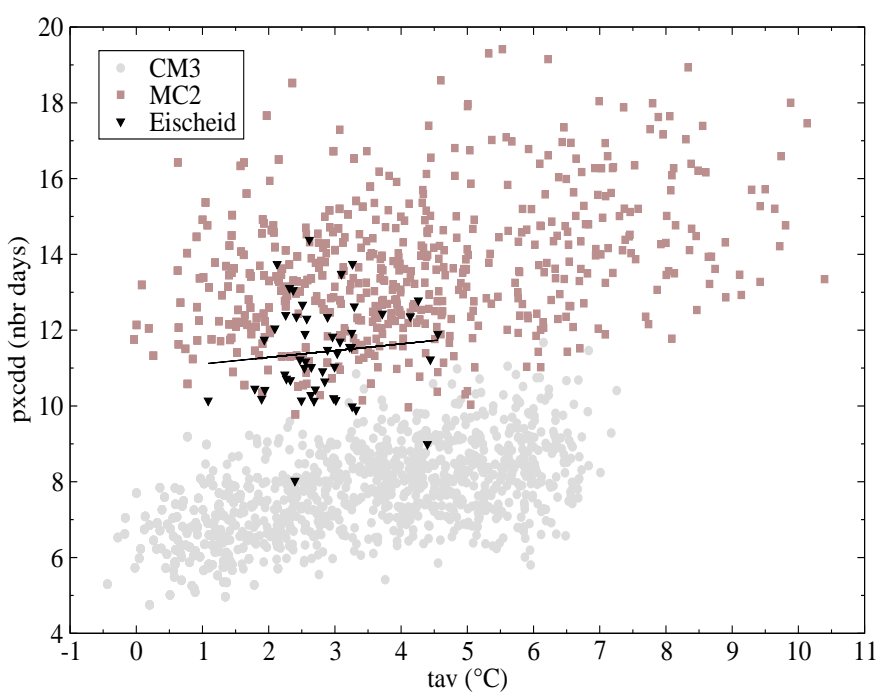

$$
\text { (av) }
$$

